\title{
Apolipoprotein E4 Causes Age- and Tau-Dependent Impairment of GABAergic Interneurons, Leading to Learning and Memory Deficits in Mice
}

\author{
Yaisa Andrews-Zwilling, ${ }^{1,5}$ Nga Bien-Ly, ${ }^{1,3}$ Qin Xu, ${ }^{1,2}$ Gang Li, ${ }^{1,5}$ Aubrey Bernardo, ${ }^{1}$ Seo Yeon Yoon, ${ }^{1}$ Daniel Zwilling, ${ }^{1,5}$ \\ Tonya Xue Yan, ${ }^{1}$ Ligong Chen, ${ }^{1}$ and Yadong Huang ${ }^{1,2,3,4,5}$ \\ ${ }^{1}$ Gladstone Institute of Neurological Disease, ${ }^{2}$ Gladstone Institute of Cardiovascular Disease, ${ }^{3}$ Biomedical Sciences Graduate Program, and Departments of \\ ${ }^{4}$ Pathology and ${ }^{5}$ Neurology, University of California, San Francisco, San Francisco, California 94158
}

\begin{abstract}
Apolipoprotein E4 (apoE4) is the major genetic risk factor for Alzheimer's disease. However, the underlying mechanisms are unclear. We found that female apoE4 knock-in (KI) mice had an age-dependent decrease in hilar GABAergic interneurons that correlated with the extent of learning and memory deficits, as determined in the Morris water maze, in aged mice. Treating apoE4-KI mice with daily peritoneal injections of the $\mathrm{GABA}_{\mathrm{A}}$ receptor potentiator pentobarbital at $20 \mathrm{mg} / \mathrm{kg}$ for 4 weeks rescued the learning and memory deficits. In neurotoxic apoE4 fragment transgenic mice, hilar GABAergic interneuron loss was even more pronounced and also correlated with the extent of learning and memory deficits. Neurodegeneration and tauopathy occurred earliest in hilar interneurons in apoE4 fragment transgenic mice; eliminating endogenous Tau prevented hilar GABAergic interneuron loss and the learning and memory deficits. The $\mathrm{GABA}_{\mathrm{A}}$ receptor antagonist picrotoxin abolished this rescue, while pentobarbital rescued learning deficits in the presence of endogenous Tau. Thus, apoE4 causes age- and Tau-dependent impairment of hilar GABAergic interneurons, leading to learning and memory deficits in mice. Consequently, reducing Tau and enhancing GABA signaling are potential strategies to treat or prevent apoE4-related Alzheimer's disease.
\end{abstract}

\section{Introduction}

Alzheimer's disease, the most common age-dependent neurodegenerative disorder, is characterized by progressive memory loss and cognitive decline (Hardy and Selkoe, 2002; Perrin et al., 2009). The neuropathological hallmarks of Alzheimer's disease are amyloid plaques, extracellular deposits of amyloid- $\beta$ (A $\beta$ ) peptides, and neurofibrillary tangles, which are intraneuronal filaments composed of hyperphosphorylated Tau (Selkoe, 1991; Crowther, 1993; Tanzi and Bertram, 2001; Brunden et al., 2009). Apolipoprotein E4 (apoE4), the major known genetic risk factor for Alzheimer's disease (Corder et al., 1993; Strittmatter et al., 1993), colocalizes with amyloid plaques and neurofibrillary tangles (Namba et al., 1991; Wisniewski and Frangione, 1992; Strittmatter et al., 1993). ApoE is a $34 \mathrm{kDa}$ protein composed of $299 \mathrm{aa}$, which exists in three major isoforms (apoE2, apoE3, and apoE4) in humans (Mahley, 1988; Weisgraber, 1994). They differ at one or two positions in their primary sequence. ApoE3 has Cys-112

Received Aug. 3, 2010; revised Aug. 23, 2010; accepted Aug. 26, 2010.

This work was supported in part by the J. David Gladstone Institutes and National Institutes of Health Grants P01 AG022074 and C06RR18928. We thank Drs. M. Vitek and H. Dawson at Duke University for providing tau knock-out mice, Dr. N. Devidze and I. Lo and P. Hampto at the Gladstone Behavioral Core for assisting on behavioral tests, and Dr. B. Halabisky for assisting on electrophysiology. We also thank J. Carroll, C. Goodfellow, and A. Wilson for graphics, S. Ordway and G. Howard for editorial assistance, and L. Turney for manuscript preparation.

Y.H. has received funding from Merck for other research on apoE4 and its role in neurodegenerative disorders.

Correspondence should be addressed to Dr. Yadong Huang, Gladstone Institute of Neurological Disease, 1650 Owens Street, San Francisco, CA 94158. E-mail: yhuang@gladstone.ucsf.edu.

DOI:10.1523/JNEUROSCI.4040-10.2010

Copyright $\odot 2010$ the authors $\quad 0270-6474 / 10 / 3013707-11 \$ 15.00 / 0$ and Arg-158, whereas apoE4 has arginines at both positions, and apoE2 has cysteines (Mahley, 1988; Weisgraber, 1994). ApoE4, found in $65-80 \%$ of cases of sporadic and familial Alzheimer's disease (Farrer et al., 1997), increases the occurrence and lowers the age of onset of the disease in a gene dose-dependent manner (Corder et al., 1993; Farrer et al., 1997). ApoE4 is also associated with cognitive impairment in humans (Caselli et al., 2009) and causes learning and memory deficits in mice (Raber et al., 1998, 2000; Hartman et al., 2001; Bour et al., 2008). Although biochemical, cell biological, transgenic animal, and clinical studies have suggested potential explanations for apoE4's contribution to the pathogenesis of Alzheimer's disease [for review, see Herz and Beffert (2000), Irizarry et al. (2000), Huang (2006a,b, 2010), Mahley et al. (2006), Hoe and Rebeck (2008), Bell and Zlokovic (2009), Bu (2009), Herz (2009), Kim et al. (2009), and Zhong and Weisgraber (2009)], the mechanisms are still unclear.

We previously reported that apoE4 impairs GABAergic interneurons in the hilus of the dentate gyrus in human apoE knock-in (KI) mice (Li et al., 2009), likely due to increased Tau phosphorylation mediated by neurotoxic apoE4 fragments (Huang, 2006b, 2010; Li et al., 2009). Interestingly, apoE4 is associated with subclinical epileptiform activity under stress (Palop and Mucke, 2009) and increased brain activity at rest and in response to memory tasks in humans (Filippini et al., 2009), probably reflecting impaired GABAergic inhibitory neuronal functions. There is evidence of GABAergic interneuron impairment in Alzheimer's disease patients, including a decrease in GABA or somatostatin levels in the brain and CSF (Davies et al., 1980; Bareggi et al., 
1982; Zimmer et al., 1984; Hardy et al., 1987; Seidl et al., 2001) that is exacerbated by apoE4 (Grouselle et al., 1998). Importantly, learning triggers a rapid increase in inhibitory synaptogenesis in the cortex and a lasting increase in GABA release from hippocampal interneurons in mice, suggesting that learning normally involves an increase in inhibitory synaptic plasticity and GABA release (Nitz and McNaughton, 2004; Cui et al., 2008; Perrin et al., 2009). We hypothesize that apoE4 causes hippocampal GABAergic interneuron impairment, leading to learning and memory deficits. In the present study, we tested this hypothesis in different mouse models of apoE.

\section{Materials and Methods}

Reagents and cell culture. Minimal essential medium (MEM), Opti-MEM, and fetal bovine serum were from Invitrogen. Primary hippocampal neuronal cultures were prepared from postnatal day 0 (P0) pups of apoE4 $(\Delta 272-299) \mathrm{mE}^{-/-} \mathrm{Tau}^{+/+}$, apoE4 $(\Delta 272-299) \mathrm{mE}^{-1-} \mathrm{Tau}^{-1-}, \mathrm{mE}^{-/-} \mathrm{Tau}^{+/+}$, $\mathrm{mE}^{-1-} \mathrm{Tau}^{-1-}$, and wild-type mice, as reported previously (Li et al., 2009). Hippocampi were isolated on $\mathrm{P} 0$, and dissociated cells were plated at 125,000 cells/ml in Neurobasal medium supplemented with $\mathrm{B} 27,100 \mathrm{U} / \mathrm{ml}$ penicillin $\mathrm{G}$, and $100 \mu \mathrm{g} / \mathrm{ml}$ streptomycin. The genotypes of cultures were determined by PCR analysis of the tails of the pups from which the cells were obtained. After $14 \mathrm{~d}$ in vitro, the cultures were fixed in $4 \%$ paraformaldehyde in PBS (135 mM NaCl, $2.7 \mathrm{~mm} \mathrm{KCl}, 43 \mathrm{~mm}$ $\mathrm{Na}_{2} \mathrm{HPO}_{4}, 14 \mathrm{~mm} \mathrm{KH} \mathrm{PO}_{4}, \mathrm{pH}$ 7.4) for $30 \mathrm{~min}$ at room temperature. After permeabilization in PBS with $0.1 \%$ Triton for $10 \mathrm{~min}$, cells were placed in blocking buffer (PBS with 10\% normal serum from the same species that produced the secondary antibody and $0.01 \%$ Triton) for $30 \mathrm{~min}$. Primary anti-GAD67 (1: 250; Millipore Bioscience Research Reagents) was applied overnight at $4^{\circ} \mathrm{C}$ and visualized with anti-mouse IgG conjugated with Alexa Fluor 488. Cells were counterstained with DAPI. To measure GABAergic neuronal survival in hippocampal neuron cultures, GAD67-positive neurons were counted in 15-30 random fields under a fluorescence microscope at $200 \times$ magnification (Li et al., 2009).

Mice and treatments. Wild-type mice and human apoE3-KI and apoE4-KI mice (Sullivan et al., 2004) were from Taconic. Tau ${ }^{-/-}$mice (Dawson et al., 2001) were backcrossed onto the $\mathrm{mE}^{-/-}$background, and $\mathrm{mE}^{-/-} \mathrm{Tau}^{-/-}$mice were crossed with apoE4 $(\Delta 272-299) \mathrm{mE}^{-/-} \mathrm{Tau}^{+/+}$ mice. Studies were conducted on female mice at 1,3, 6, 12, 16, or 21 months of age. All mice were on a C57BL/6 genetic background. Some apoE4-KI and apoE4 $(\Delta 272-299) \mathrm{mE}^{-1-} \mathrm{Tau}^{+/+}$mice received daily intraperitoneal injections of pentobarbital $(20 \mathrm{mg} / \mathrm{kg})$ or saline in their home cages for $21 \mathrm{~d}$ before the first day of the Morris water maze training and $1 \mathrm{~h}$ after daily training. Some apoE4 $(\Delta 272-299) \mathrm{mE}^{-1-} \mathrm{Tau}^{-1-}$ mice were given daily injections of picrotoxin $(1 \mathrm{mg} / \mathrm{kg})$ or saline intraperitoneally in their home cages for $3 \mathrm{~d}$ before the Morris water maze training and 30 min before daily training. Brain tissues were collected after a $1 \mathrm{~min}$ transcardial perfusion with $0.9 \% \mathrm{NaCl}$. One hemibrain from each mouse was fixed in $4 \%$ paraformaldehyde, sectioned $(30 \mu \mathrm{m})$ with a microtome, and immunostained as described below. All experiments were performed in accordance with National Institutes of Health and institutional guidelines.
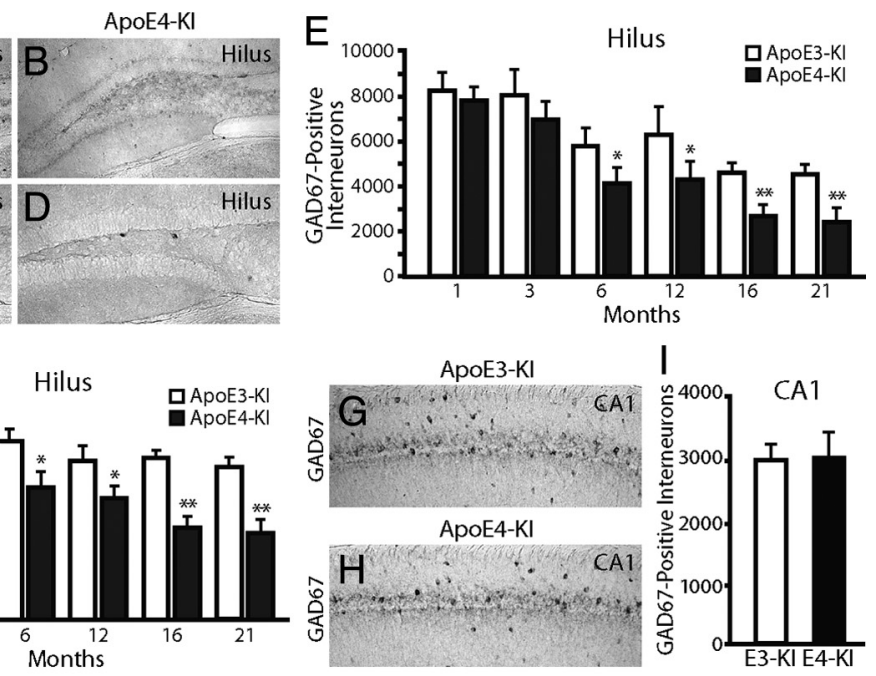

Month

$\mathrm{L}$
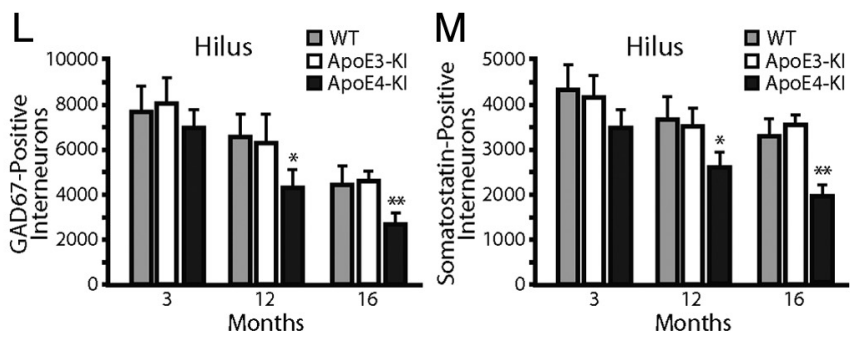

in apoE4-KI mice. $\boldsymbol{A}-\boldsymbol{D}$, Representative photomicrographs $(200 \times)$ from female apoE3-KI and apoE4-KI mice at 16 months of age show GABAergic interneurons in the hilus after staining with anti-GAD67 $(\boldsymbol{A}, \boldsymbol{B})$ and anti-somatostatin $(\boldsymbol{C}, \boldsymbol{D}) . \boldsymbol{E}, \boldsymbol{F}$, Hilar GABAergic interneurons positive for GAD67 $(\boldsymbol{E})$ or somatostatin $(\boldsymbol{F})$ in female apoE3-KI and apoE4-KI mice at 1, 3, 6, 12, 16, and 21 months of (n) $=12$ mice per group) were quantified as described in Materials and Methods. Values are mean \pm SEM. ${ }^{*} p<0.05$;

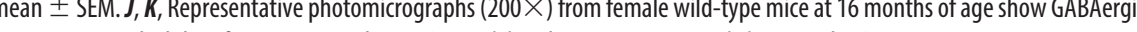
eurons in the hilus after staining with anti-GAD67 $(\boldsymbol{J})$ and anti-somatostatin $(\boldsymbol{K}) . \boldsymbol{L}, \boldsymbol{M}$, Hilar GABAergic interneurons positive ( mice per group) were quantified as described in Materials and Methods. Values are mean $\pm S E M .{ }^{*} p<0.05 ;{ }^{* *} p<0.01$ versus wild-type and apoE3-KI mice at the same age ( $t$ test).

Immunohistochemistry and image collection. Sliding microtome sections $(30 \mu \mathrm{m})$ were immunostained with the following primary antibodies: polyclonal goat anti-human apoE (1:8000 for fluorescence; Calbiochem), rabbit anti-neuropeptide Y (1:8000 for DAB; ImmunoStar), rat anti-somatostatin (1:100 for DAB; Millipore Bioscience Research Reagents), mouse anti-GAD67 (1:1000 for DAB; Millipore Bioscience Research Reagents), mouse anti-MAP2 (1:500 for fluorescence; Sigma), mouse anti-synaptophysin (1:500 for fluorescence; DakoCytomation), and phosphorylation-dependent monoclonal antibody AT8 (p-Ser202 and p-Thr205; 1:100 for DAB; Endogen). Primary antibodies were detected with biotinylated goat anti-rabbit or goat anti-rat IgG (both 1:200; Vector Laboratories), Alexa Fluor 488-labeled goat antirabbit IgG (1:2000; Invitrogen), or Alexa Fluor 594-labeled donkey antimouse IgG (1:2000; Invitrogen). Stained sections were examined with a Radiance 2000 laser-scanning confocal system (Bio-Rad) mounted on a Nikon Optiphot-2 microscope. Images were processed with Photoshop CS (Adobe Systems).

Quantitative analyses of immunostained brain sections. GABAergic interneurons in the hilus of the dentate gyrus were quantified by counting GAD67-, NPY-, and somatostatin-positive cells in every 10th serial coronal section throughout the rostrocaudal extent of the hippocampus by an investigator blinded to genotype and treatment (Li et al., 2009). Results are presented as the total number of positive cells counted per hemibrain multiplied by 2 (for both hemibrains), and then by 10 (for every 10th serial section). 

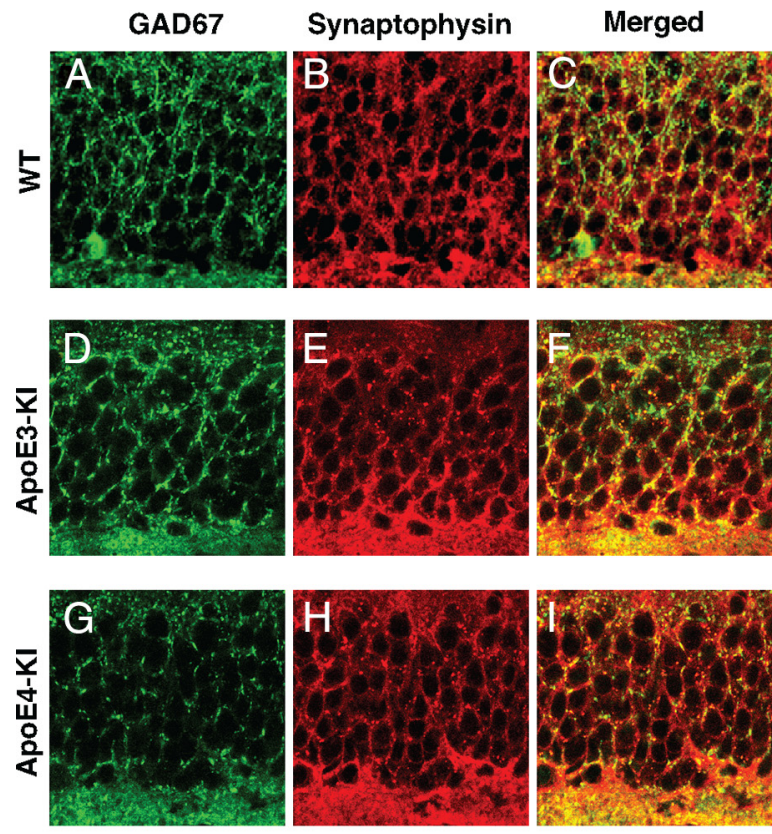
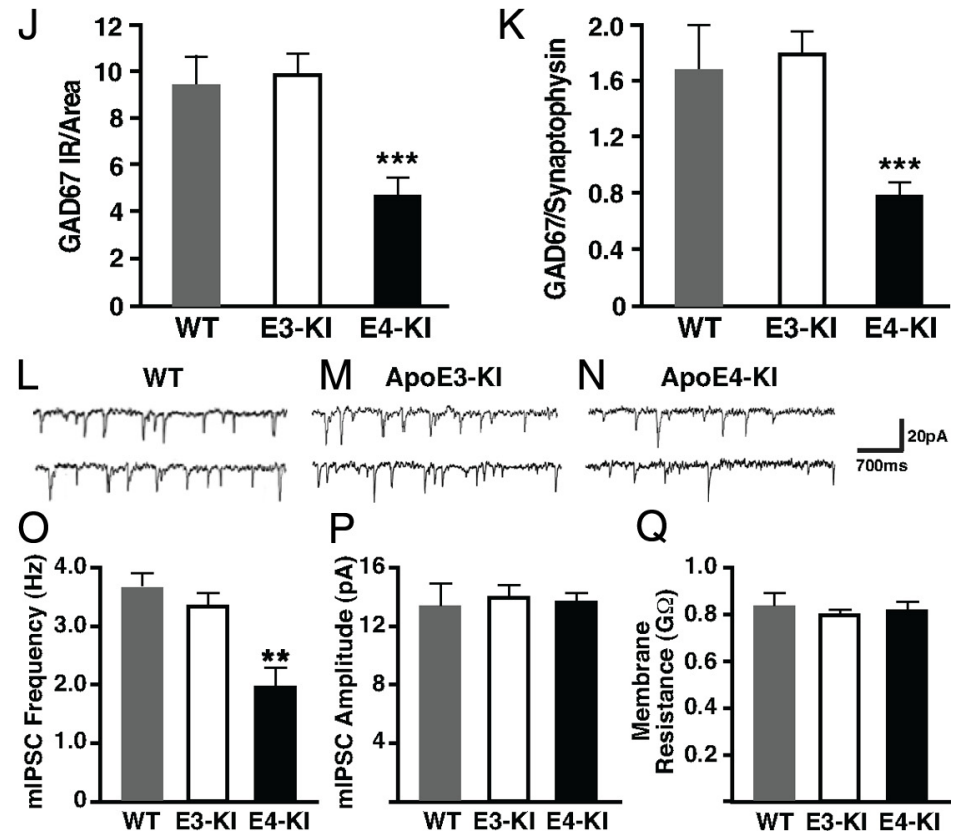

Figure 2. Presynaptic GABAergic input onto granule cells is reduced in female apoE4-KI mice. $A-I$, Representative confocal images of the granule cell layer of the dentate gyrus of female wild-type $(\boldsymbol{A}-\boldsymbol{C})$, apoE3-KI (D-F), and apoE4-KI (G-I) mice at 16 months of age stained with anti-GAD67 $(\boldsymbol{A}, \boldsymbol{D}, \boldsymbol{G})$ and anti-synaptophysin $(\boldsymbol{B}, \boldsymbol{E}, \boldsymbol{H})$. Merged images are shown in $\boldsymbol{C}, \boldsymbol{F}$, and $\boldsymbol{I}$. $\boldsymbol{J}, \mathbf{G A D 6 7}$ immunoreactivity (IR) of sections from different mice was quantified and normalized by area. Values are mean \pm SEM (four images per mouse and $4-5$ mice per genotype). ${ }^{* * *} p<0.005$ versus wild-type and apoE3-KI mice ( $t$ test). $\boldsymbol{K}$, The ratio of GAD67-IR to synaptophysin-IR (a general presynaptic marker) in sections from different mice. Values are mean \pm SEM (four images per mouse and $4-5$ mice per genotype). ${ }^{* *} p<0.005$ versus wild-type and apoE3-KI mice ( $t$ test). $\boldsymbol{L}-\boldsymbol{N}$, Traces of miniature IPSCs (mIPSCs) in granule cells from wild-type ( $\boldsymbol{L}$ ), apoE3-KI $(\boldsymbol{M})$, or apoE4-KI $(\boldsymbol{N})$ mice during whole-cell voltage-clamp recording in the presence of DNQX (20 $\mu \mathrm{m}), \mathrm{D}-\mathrm{AP5}(50 \mu \mathrm{m})$, and TTX (1 $\mu \mathrm{m})$. Calibration: $20 \mathrm{pA}, 700 \mathrm{~ms}$. 0, Average mIPSC frequency in granule cells was lower in apoE4-KI mice than in wild-type and apoE3-KI mice. Values are mean \pm SEM ( $n=9-11$ cells from 3 to 4 mice per genotype). ${ }^{* *} p<0.01$ versus wild-type and apoE3-KI mice ( $t$ test). $\boldsymbol{P}$, Average mIPSC amplitude in granule cells was similar in wild-type, apoE3-KI, and apoE4-KI mice. Values are mean \pm SEM ( $n=9-11$ cells from 3 to 4 mice per genotype). $\mathbf{Q}$, Average membrane resistance of granule cells was similar in wild-type, apoE3-KI, and apoE4-KI mice. Values are mean \pm SEM ( $n=8-11$ cells from 3 to 4 mice per genotype).

Morris water maze. The water maze pool (diameter, $122 \mathrm{~cm}$ ) contained opaque water $\left(22-23^{\circ} \mathrm{C}\right)$ with a platform $10 \mathrm{~cm}$ in diameter. The platform was submerged $1.5 \mathrm{~cm}$ during hidden platform sessions (Raber et al., 1998; Harris et al., 2003; Roberson et al., 2007) and marked with black-and-white-striped mast $(15 \mathrm{~cm}$ high) during cued training sessions. Mice were trained to locate the hidden platform (hidden days 1-5) and the cued platform (visible days $1-3)$ in two daily sessions (3.5 h apart), each consisting of two $60 \mathrm{~s}$ trials (hidden and cued training) with a 15 min intertrial interval. The platform location remained constant in the hidden platform sessions but was changed for each cued platform session. Entry points were changed semirandomly between trials. Twenty-four, seventy-two, and one hundred twenty hours after the last hidden platform training, a $60 \mathrm{~s}$ probe trial (platform removed) was performed. Entry points for the probe trial were in the west quadrant, and the target quadrant was the southeast quadrant. Performance was monitored with an EthoVision video-tracking system (Noldus Information Technology). The data were presented as percentage time spent and platform crossings. Percentage time spent compares the time spent in the target quadrant to the average time spent in the other three quadrants. Platform crossings compare the number of crossings over the position of the target platform to the average number of crossings over the equivalent position of the platform in the other three quadrants.

Elevated plus maze. The elevated plus maze tests "emotionality" and unconditioned anxiety-related behaviors that involve a conflict between the rodent's desire to explore a novel environment and anxiogenic elements such as elevation and an unfamiliar, brightly illuminated area (Roberson et al., 2007). The maze consists of two open arms and two closed arms equipped with rows of infrared photocells interfaced with a computer (Hamilton). Mice were placed individually into the center of the maze and allowed to explore for $10 \mathrm{~min}$. The number of beam breaks was recorded to calculate the amount of time spent and distance moved in each arm and the number of entries into the open and closed arms. After each mouse was tested, the maze was cleaned with $70 \%$ ethanol to standardize odors.
Electrophysiology. Wild-type, ApoE3-KI, and apoE4-KI mice were killed and processed for slice preparation as described previously (Li et al., 2009). Brains were quickly removed into an ice-cold solution containing (in mM) 110 choline chloride, $2.5 \mathrm{KCl}, 1.3 \mathrm{KH}_{2} \mathrm{PO}_{4}, 25 \mathrm{NaHCO}_{3}$, $0.5 \mathrm{CaCl}_{2}, 7 \mathrm{MgCl}_{2}, 10$ dextrose, 1.3 sodium ascorbate, and 0.6 sodium pyruvate (300-305 mOsm). Horizontal slices (350 $\mu \mathrm{m}$ thick) were cut with a Vibratome, maintained in continuously oxygenated external solution (in mm: $125 \mathrm{NaCl}, 2.5 \mathrm{KCl}, 1.3 \mathrm{KH}_{2} \mathrm{PO}_{4}, 25 \mathrm{NaHCO}_{3}, 2 \mathrm{CaCl}_{2}, 1.3$ $\mathrm{MgCl}_{2}, 1.3$ sodium ascorbate, 0.6 sodium pyruvate, 10 dextrose, $\mathrm{pH} 7.4$ ) at $30^{\circ} \mathrm{C}$ for at least $40 \mathrm{~min}$, and incubated at room temperature for at least $60 \mathrm{~min}$ before recording. Whole-cell voltage-clamp recordings from dentate gyrus granule cells were obtained with an infrared differential interference contrast video microscopy system. Patch electrodes (3-6 $\mathrm{M} \Omega$ ) were pulled from borosilicate glass capillary tubing (World Precision Instruments) on a horizontal Flaming-Brown microelectrode puller (model P-97, Sutter Instruments). Intracellular patch pipette solution contained (in mM) 120 Cs-gluconate, $10 \mathrm{HEPES}, 0.1 \mathrm{EGTA}, 15 \mathrm{CsCl}_{2}, 4$ $\mathrm{MgCl}_{2}, 4 \mathrm{Mg}$-ATP, and 0.3 $\mathrm{Na}_{2}$-GTP, pH 7.25 (285-290 mOsm). To measure mIPSCs, slices were perfused with artificial CSF containing 20 $\mu \mathrm{M}$ 6,7-dinitroquinoxaline-2,3-dione (DNQX), $50 \mu \mathrm{M} \mathrm{D}$-(-)-2-amino5-phosphonovaleric acid (D-AP5), and $1 \mu \mathrm{M}$ tetrodotoxin (TTX). Whole-cell voltage-clamp data were low-pass filtered at $6 \mathrm{kHz}(-3 \mathrm{~dB}$, eight-pole Bessel), digitally sampled at $10 \mathrm{kHz}$ with a Multiclamp 700A amplifier (Molecular Devices), and acquired with a Digidata-1322 digitizer and pClamp 9.2 software (Molecular Devices). Whole-cell access resistance was monitored throughout the recording, and cells were rejected if values changed by $>25 \%$. mIPSCs were analyzed with a program provided by Dr. John Huguenard (Stanford University, Stanford, CA).

Statistical analyses. Values are expressed as mean \pm SEM or mean \pm SD. Statistical analyses were performed with GraphPad Prism, Statview 5.0 (SAS Institute) or SPSS-10 (SPSS). Differences between means were assessed by $t$ test, Mann-Whitney $U$ test, one-factor ANOVA, or twofactor ANOVA, followed by Bonferroni, Tukey-Kramer, or Fisher's PLSD post hoc tests. $p<0.05$ was considered statistically significant. 


\section{Results}

Age-dependent decrease in GABAergic interneurons in the hilus of dentate gyrus of female apoE4-KI mice To assess the effect of aging and apoE4 on GABAergic interneurons in the hippocampus, we first quantified their numbers in the hilus of dentate gyrus of female apoE3-KI and apoE4-KI mice at 1, 3, 6, 12, 16 , and 21 months of age. We studied female mice because they are susceptible to apoE4-induced learning and memory deficits (Raber et al., 1998, 2000). AntiGAD67 and anti-somatostatin immunostaining, as shown representatively in 16-month-old apoE3-KI and apoE4-KI mice (Fig. $1 A-D$ ), revealed a significantly greater age-dependent decrease in GABAergic interneurons in the hilus of the dentate gyrus of female apoE4-KI mice than in age- and sex-matched apoE3-KI mice (ANOVA; GAD67, age, $F_{(1,5)}=22.65, p<0.001$; apoE genotype, $F_{(1,5)}=21.74, p<0.001$; interaction, $F_{(1,5)}=0.4601, p>0.05$; somatostatin, age, $F_{(1,5)}=4.972, p<0.001$; apoE genotype, $F_{(1,5)}=29.6, p<0.001$; interaction, $F_{(1,5)}=$ $1.335, p>0.05$ ) (Fig. $1 E, F)$. The significant difference between apoE4-KI and apoE3-KI mice was first observed at 6 months (twotailed $t$ test; GAD67, $t_{(6)}=2.963, p<0.05$; somatostatin, $\left.t_{(6)}=5.455, p<0.05\right)$ and was most pronounced at 16 (two-tailed $t$ test; GAD67, $t_{(20)}=2.628, p<0.01$; somatostatin, $\left.t_{(20)}=4.334, p<0.01\right)$ and 21 (two-tailed $t$ test; GAD67, $t_{(14)}=3.503, p<$ 0.01 ; somatostatin, $t_{(14)}=3.637, p<0.01$ ) months (Fig. 1E,F). ApoE3-KI mice had a milder age-dependent decrease in hilar GABAergic interneurons (Fig. 1E,F). Interestingly, the number of GABAergic interneurons in the hippocampal CA1 area did not differ in apoE3-KI and apoE4-KI mice at 16 months (Fig. 1G$I)$, suggesting a region-specific detrimental effect of apoE4 on GABAergic interneurons. As controls, female wildtype mice at 3,12 , and 16 months of age were also included in the study. At all three ages, the numbers of hilar GABAergic interneurons in wild-type mice were similar to those in apoE3-KI mice (Fig. $1 J-M$ ). Thus, as compared to mouse apoE, human apoE3 has no effect, but human apoE4 has a detrimental effect, on hilar GABAergic interneurons.

Presynaptic GABAergic input onto granule cells is reduced in female apoE4-KI mice

The axonal termini of GABAergic interneurons on granule cells in the dentate gyrus of female wild-type, apoE3-KI, and apoE4-KI mice at 16 months of age were assessed by anti-GAD67 and antisynaptophysin double immunofluorescence staining and confomonths of age.
A
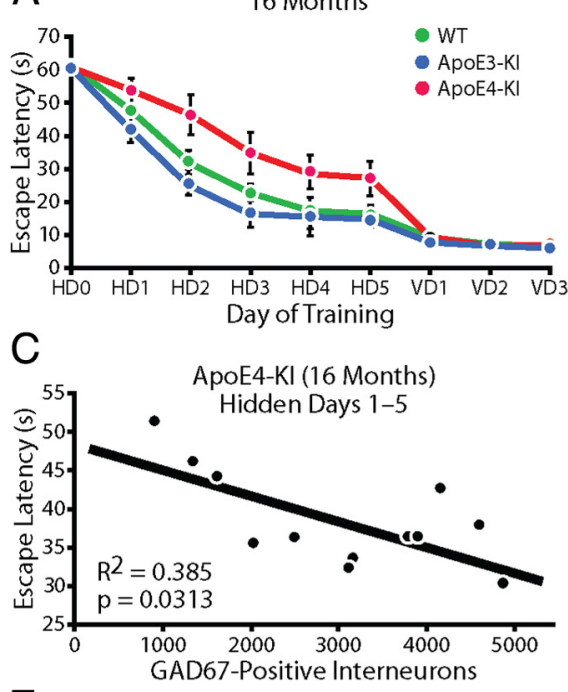

E
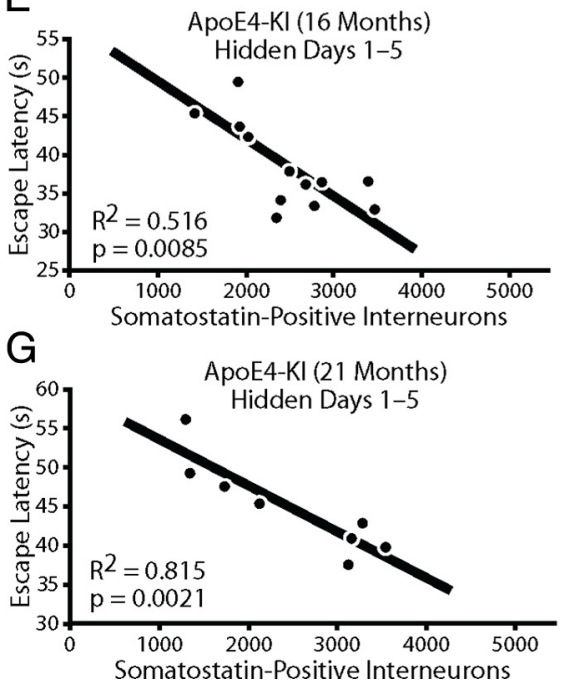

B
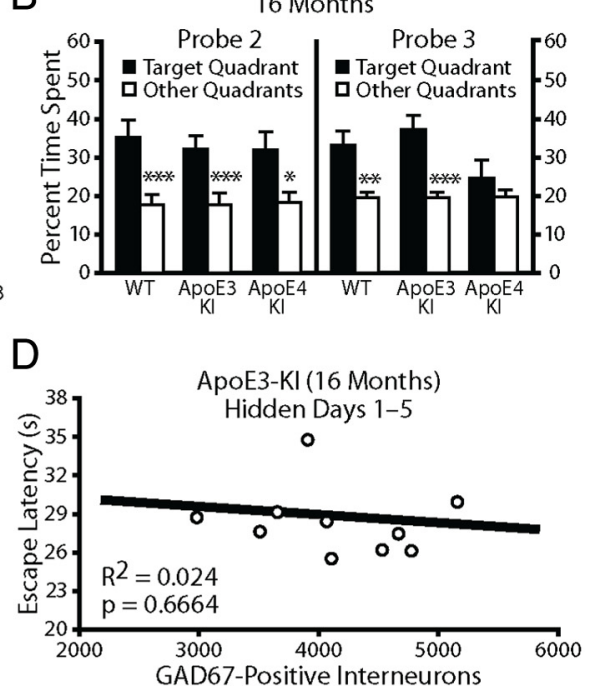

F

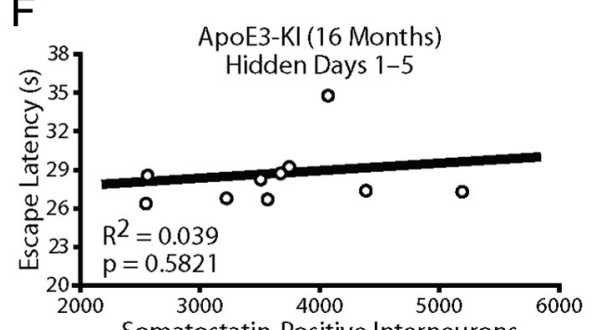

$\mathrm{H}$

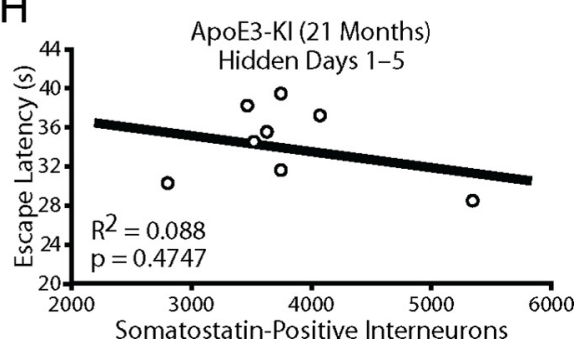

Figure 3. Correlation of hilar GABAergic interneuron impairment with spatial learning deficits in apoE4-KI mice. $\boldsymbol{A}$, Nine wild-type, ten apoE3-KI, and twelve apoE4-KI female mice were tested at 16 months of age in the Morris water maze. Points represent averages of daily trials. HD, hidden platform day (2 trials/session, 2 sessions/d); HDO, first trial on HD1; VD, visible platform day (2 trials/session, 2 sessions/d). $y$-Axis indicates time to reach the target platform (escape latency, mean \pm SEM). In the hidden platform days, learning curves differed significantly by genotypes (repeated-measures ANOVA, $p<0.01$ ). In post hoc comparisons, apoE4-KI mice learned poorly ( $p<0.01$ versus other groups). Wild-type and apoE4-KI mice performed at a similar level. $\boldsymbol{B}$, The probe trials of female wild-type, apoE3-KI, and apoE4-KI mice at 16 months of age were performed $72 \mathrm{~h}$ (probe 2 ) and $120 \mathrm{~h}$ (probe 3) after the last hidden platform training. Percentage time spent in the target quadrant versus the average time spent in other quadrants differed by genotype in probe $3(p<0.05)$. Values are mean \pm SEM. ${ }^{*} p<0.05,{ }^{* *} p<0.01,{ }^{* * *} p<0.005$ ( $t$ test). $C, D$, Escape latency in hidden platform days $1-5$ correlated inversely with the number of GAD67-positive hilar GABAergic interneurons in apoE4-KI mice $(\boldsymbol{C}, n=12)$ but not apoE3-KI mice $(\boldsymbol{D}, n=10)$ at 16 months of age. $\boldsymbol{E}, \boldsymbol{F}$, Escape latency in hidden platform days $1-5$ correlated inversely with the number of somatostatin-positive hilar GABAergic interneurons in apoE4-KI mice $(\boldsymbol{E}, n=12)$ but not apoE3-KI mice $(\boldsymbol{F}, n=10)$ at 16 months of age. $\boldsymbol{G}, \boldsymbol{H}$, Eight apoE3-KI and eight apoE4-KI female mice were tested at 21 months of age in the Morris water maze. Escape latency in hidden platform days $1-5$ correlated inversely with the number of somatostatin-positive hilar GABAergic interneurons in apoE4-KI mice $(\boldsymbol{G}, n=8)$ but not apoE3-KI mice $(\boldsymbol{H}, n=8)$ at 21

cal imaging analysis. The GABAergic axonal termini on granule cells were significantly decreased at the absolute level (GAD67 fluorescence intensity) and relative to the presynaptic marker synaptophysin (GAD67/synaptophysin ratio) in apoE4-KI mice as compared to wild-type (two-tailed $t$ test; GAD67, $t_{(16)}=3.112$, $p<0.005$; GAD67/Syn, $\left.t_{(16)}=3.076, p<0.005\right)$ and apoE3-KI (two-tailed $t$ test; GAD67, $t_{(20)}=5.677, p<0.005$; GAD67/Syn, $\left.t_{(20)}=5.678, p<0.005\right)$ mice (Fig. $\left.2 A-K\right)$. To assess the functional consequence of this finding, we performed whole-cell 

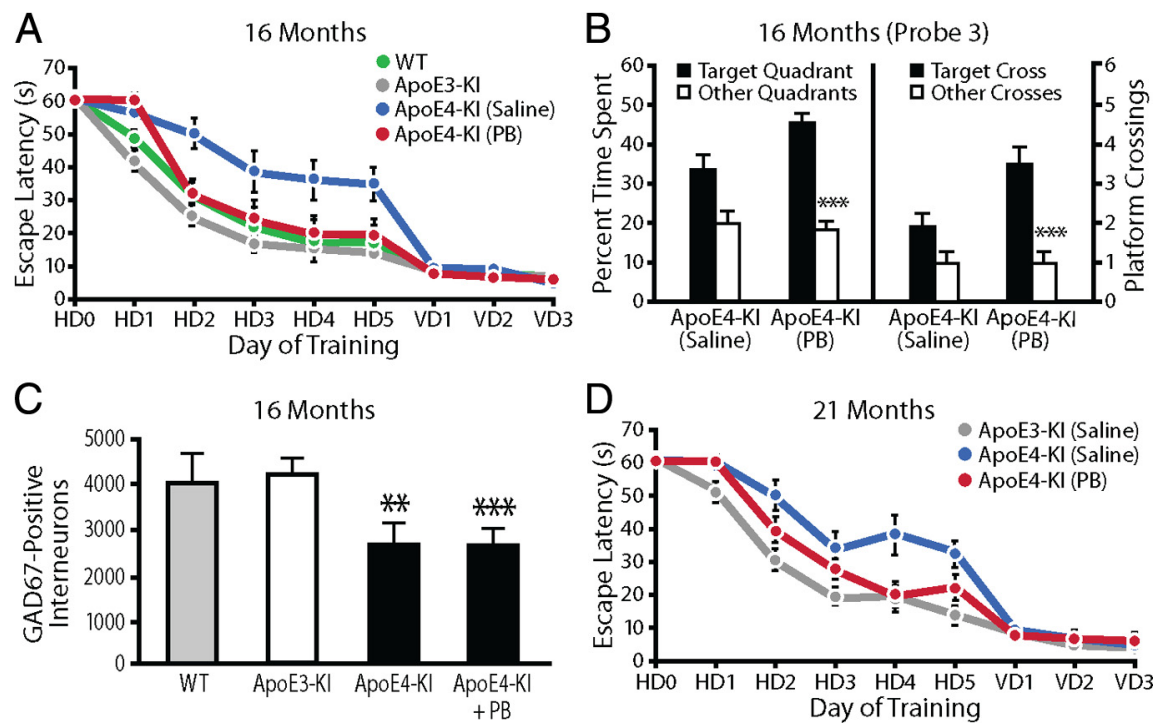

Figure 4. $\mathrm{GABA}_{\mathrm{A}}$ receptor potentiator pentobarbital rescues spatial learning and memory deficits in apoE4-KI mice. $\boldsymbol{A}$, Female 16-month-old apoE4-KI mice were treated with pentobarbital (PB, $20 \mathrm{mg} / \mathrm{kg}$ i.p.) or saline ( $n=6-13$ mice per group) for $21 \mathrm{~d}$ before and daily during the Morris water maze test. Untreated wild-type $(n=9)$ and apoE3-KI $(n=10)$ mice served as controls. The learning curve of pentobarbital-treated apoE4-KI mice differed from that of saline-treated apoE4-KI mice (repeated-measures ANOVA, $p<0.05$ ) but resembled that of untreated wild-type and apoE3-KI mice. Values are mean \pm SEM. HD, Hidden day; VD, visible day. $\boldsymbol{B}$, In the third probe trial $120 \mathrm{~h}$ after the last hidden session, pentobarbital treatment rescued memory deficits in 16-month-old apoE4-KI mice in the target quadrant and target cross tests ( $n=6-13$ mice per group). Values are mean \pm SEM. ${ }^{* * *} p<0.005$ ( $t$ test). C, Total number of GAD67-positive GABAergic interneurons in the hilus of wild-type mice, apoE3-KI mice, apoE4-KI mice, and apoE4-KI mice treated with pentobarbital. Values are mean \pm SEM. ${ }^{* *} p<0.01$, ${ }^{* * *} p<0.005$ versus wild-type and apoE3-KI mice ( $t$ test). D, Female 21-month-old apoE4-KI mice were treated with pentobarbital (PB, $20 \mathrm{mg} / \mathrm{kg})$ or saline ( $n=8$ per group) for $21 \mathrm{~d}$ before and daily during the Morris water maze test. Saline-treated apoE3-KI mice $(n=8)$ served as controls. The learning curve of pentobarbital-treated apoE4-KI mice differed from that of saline-treated apoE4-KI mice (repeated-measures ANOVA, $p<0.05$ ) but resembled that of saline-treated apoE3-KI mice. Values are mean \pm SEM. HD, Hidden day; VD, visible day.

patch-clamp recordings from granule cells; glutamate currents were blocked with DNQX $(20 \mu \mathrm{M})$ and D-AP5 $(50 \mu \mathrm{M})$, and action potential-mediated GABA release was blocked with TTX $(1 \mu \mathrm{M})$. Consistent with the above findings, the frequency of miniature IPSCs (mIPSCs) was $\sim 40 \%$ lower in apoE4-KI mice than in wild-type (two-tailed $t$ test; $t_{(19)}=2.816, p<0.01$ ) and apoE3-KI (two-tailed $t$ test; $t_{(18)}=2.712, p<0.01$ ) mice (Fig. $2 L-O)$. The mIPSC amplitude and membrane resistance were not altered significantly (Fig. 2P,Q). These results suggest that apoE4-KI mice have fewer functional GABAergic synapses onto granule cells.

\section{Hilar GABAergic interneuron impairment precedes learning and memory deficits in female apoE4-KI mice}

Next, we tested spatial learning and memory of female wild-type, apoE3-KI, and apoE4-KI mice at 12, 16, and 21 months of age in the Morris water maze. At 12 months, wild-type, apoE3-KI, and apoE4-KI mice performed equally well in the hidden platform and probe trials (not shown), suggesting normal learning and memory in all three groups. At 16 months, wild-type and apoE3-KI mice quickly learned to find the hidden platform, which requires spatial learning, but apoE4-KI mice showed deficits (repeated-measures ANOVA; $F_{(2,28)}=9.217, p<0.01$; post hoc comparisons; E4-KI vs E3-KI, $t_{(20)}=3.521, p<0.01$; E4-KI vs $\mathrm{WT}, t_{(19)}=2.927, p<0.01$ ) (Fig. $3 A$ ). Similar learning deficits were found in apoE4-KI mice at 21 months of age (Fig. 4D). Swim speeds did not differ among the three groups of mice (supplemental Fig. $1 A$, available at www.jneurosci.org as supplemental material), indicating that the impairment was not due to motor deficits. Wild-type, apoE3-KI, and apoE4-KI mice performed equally well in visible platform trials (Figs. $3 A, 4 D$ ). In the probe trial $120 \mathrm{~h}$ after the last hidden platform trial, 16-month-old apoE4-KI mice had a deficit potentially in memory retention (Fig. 3B, probe 3 ), although they performed as well as wild-type and apoE3-KI mice in probe trials at 24 (supplemental Fig. $1 B$, available at www. jneurosci.org as supplemental material) and $72 \mathrm{~h}$ (Fig. 3B, probe 2). Thus, hilar GABAergic interneuron impairment, first observed at 6 months of age, precedes the learning and memory deficits, which were first observed at 16 months of age, in apoE4-KI mice.

\section{Hilar GABAergic interneuron impairment correlates with spatial learning deficits in female apoE4-KI mice}

In days $1-5$ of the hidden platform trials, the number of hilar GABAergic interneurons correlated inversely with escape latency of apoE4-KI mice (GAD67, $R^{2}=$ $0.385, p<0.05, n=12$; somatostatin, $R^{2}=0.516, p<0.01, n=12$ ), but not apoE3-KI and wild-type mice, at 16 months of age (Fig. 3C-F; supplemental Fig. $2 A, B$, available at www.jneurosci.org as supplemental material); no correlation was observed in visible platform trials (supplemental Figs. 2C,D, $3 A-D$, available at www.jneurosci.org as supplemental material). Similar results were obtained in apoE3-KI and apoE4-KI mice at 21 months of age (Fig. 3G,H; supplemental Fig. $3 E, F$, available at www. jneurosci.org as supplemental material). Interestingly, at both ages, all apoE3-KI and wild-type mice had $>2500$ hilar GABAergic interneurons (Fig. 3D,F,H; supplemental Fig. 2, available at www.jneurosci.org as supplemental material), whereas $\sim 50 \%$ of the apoE4-KI mice had $<2500$ (Fig. 3C,E, G) and had greater learning deficits in the hidden platform trials (Fig. 3C, $E, G$ ).

We then looked at the individual numbers of hilar GABAergic interneurons in female apoE4-KI mice at 6 or 12 months of age, when they also had, on average, significantly fewer hilar GABAergic interneurons than apoE3-KI and wild-type mice at similar ages (Fig. $1 E, F, L, M)$. Interestingly, none of those mice had $<2500$ hilar GABAergic interneurons, and none of those mice had learning and memory deficits at 12 months, as mentioned above. Thus, 2500 might be the threshold number of hilar GABAergic interneurons that determines normal versus impaired learning performance of female mice in the Morris water maze.

\section{Pentobarbital rescues spatial learning and memory deficits in female apoE4-KI mice}

To determine whether the loss of GABAergic interneurons contributes directly to the learning and memory deficits, we treated 16-month-old female apoE4-KI mice with daily peritoneal injections of the $\mathrm{GABA}_{\mathrm{A}}$ receptor potentiator pentobarbital at 20 $\mathrm{mg} / \mathrm{kg}$ for 4 weeks. This treatment rescued the learning and memory deficits (Fig. $4 A, B$ ) but did not alter the number of hilar 
GABAergic interneurons (Fig. 4C). The learning deficit was also rescued in 21month-old female apoE4-KI mice by pentobarbital treatment (Fig. 4D).

\section{Alzheimer's disease-like neurodegeneration occurs in transgenic mice expressing low levels of apoE4 $(\Delta 272-299)$}

We reported that neurons under stress, including neurons cultured in vitro (Harris et al., 2004a; Xu et al., 2008), express apoE and that neuronal apoE undergoes proteolytic cleavage to generate neurotoxic fragments, with apoE4 being more susceptible to the cleavage than apoE3 (Huang et al., 2001; Harris et al., 2003; Brecht et al., 2004). In primary hippocampal neuronal cultures, apoE4 impairs the survival of GABAergic interneurons by generating more neurotoxic apoE fragments and increasing the levels of phosphorylated Tau (p-Tau) (Li et al., 2009).

To assess the contributions of apoE4 fragments and p-Tau to hilar GABAergic interneuron impairment and behavioral deficits in vivo, we studied transgenic mice expressing low levels of apoE4 $(\Delta 272-$ 299), a major neurotoxic fragment in mouse and Alzheimer's disease brains (Harris et al., 2003; Brecht et al., 2004), under the control of the neuron-specific Thy-1 promoter. These mice develop Alzheimer's disease-like neurodegeneration and spatial learning and memory deficits (Harris et al., 2003). To eliminate confounding effects of mouse apoE, we crossed the original apoE4 $(\Delta 272-299)$ transgenic line with apoE knock-out $\left(\mathrm{mE}^{-1-}\right)$ mice to generate apoE4 $(\Delta 272-$ 299) $\mathrm{mE}^{-1-} \mathrm{Tau}^{+/+}$mice. To assess the effect of tau removal on Alzheimer's disease-like neuronal and behavioral deficits caused by apoE4 fragments, we crossed apoE4( $\Delta 272-299) \mathrm{mE}^{-1-} \mathrm{Tau}^{+/-}$mice with $\mathrm{mE}^{-1-} \mathrm{Tau}^{+/-}$mice to generate littermates of apoE4 $(\Delta 272-299) \mathrm{mE}^{-/-} \mathrm{Tau}^{+/+}$, apoE4 $(\Delta 272-299) \mathrm{mE}^{-1-} \mathrm{Tau}^{-1-}, \mathrm{mE}^{-1-} \mathrm{Tau}^{+/+}$, and $\mathrm{mE}^{-/-} \mathrm{Tau}^{-1-}$ mice. Eliminating endogenous tau did not alter the expression levels of apoE4( $\Delta 272-299)$ (not shown). Age- and sex-matched wild-type mice were included as controls.

Morphological studies revealed neuronal deficits in the hippocampus of 12-month-old apoE4 $(\Delta 272-299) \mathrm{mE}^{-1-} \mathrm{Tau}^{+/+}$mice, including presynaptic accumulation of apoE4 fragments as determined by antiapoE and anti-synaptophysin (a presynaptic marker) or anti-MAP2 (a dendritic marker) double immunostaining (Fig. $5 A-F)$, neurodegeneration as determined by hematoxylin/eosin and anti-MAP2 im-
ApoE4(4272-299)Tau+/+
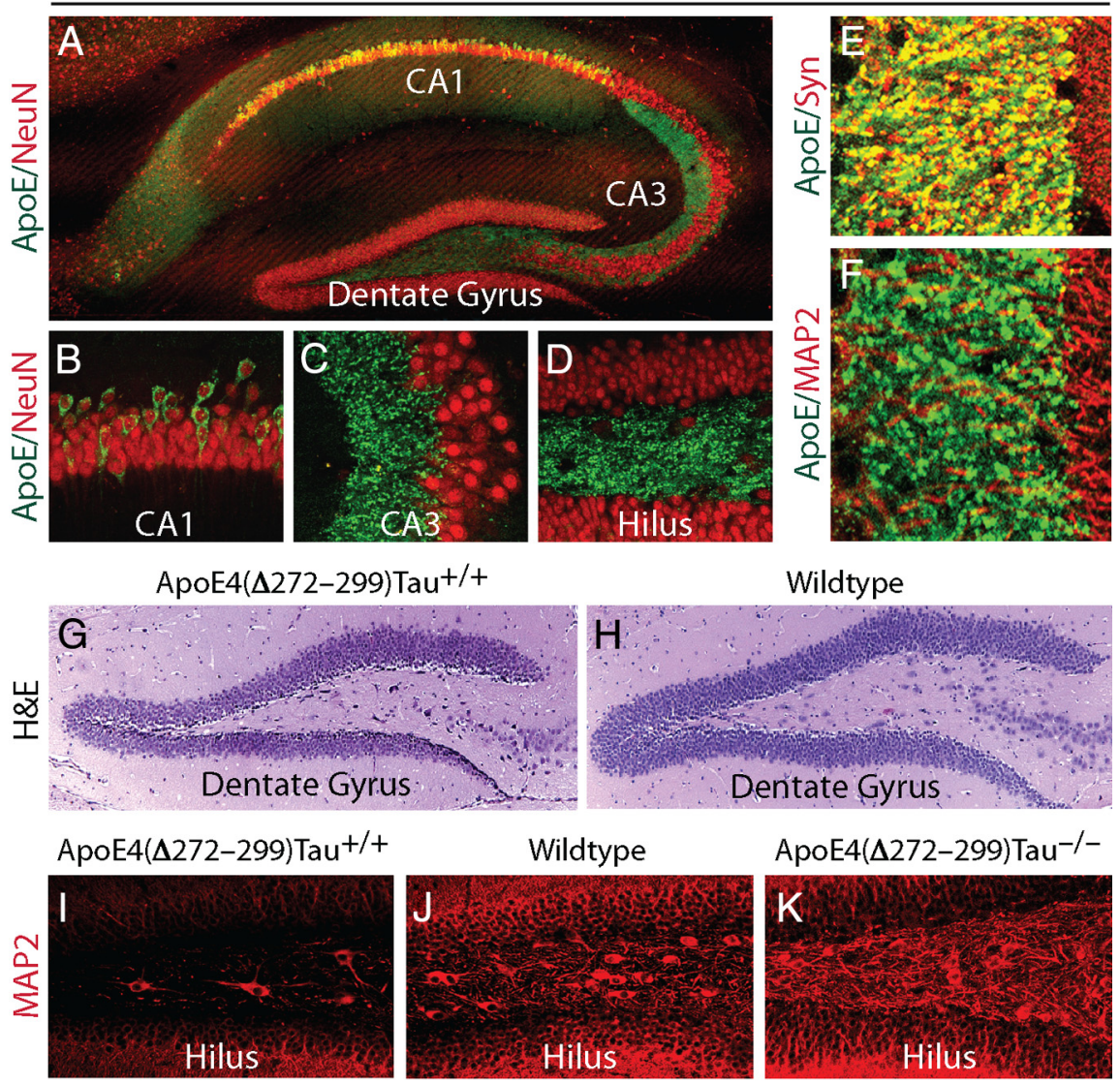

ApoE4( $\Delta 272-299) \mathrm{Tau}^{-/-}$
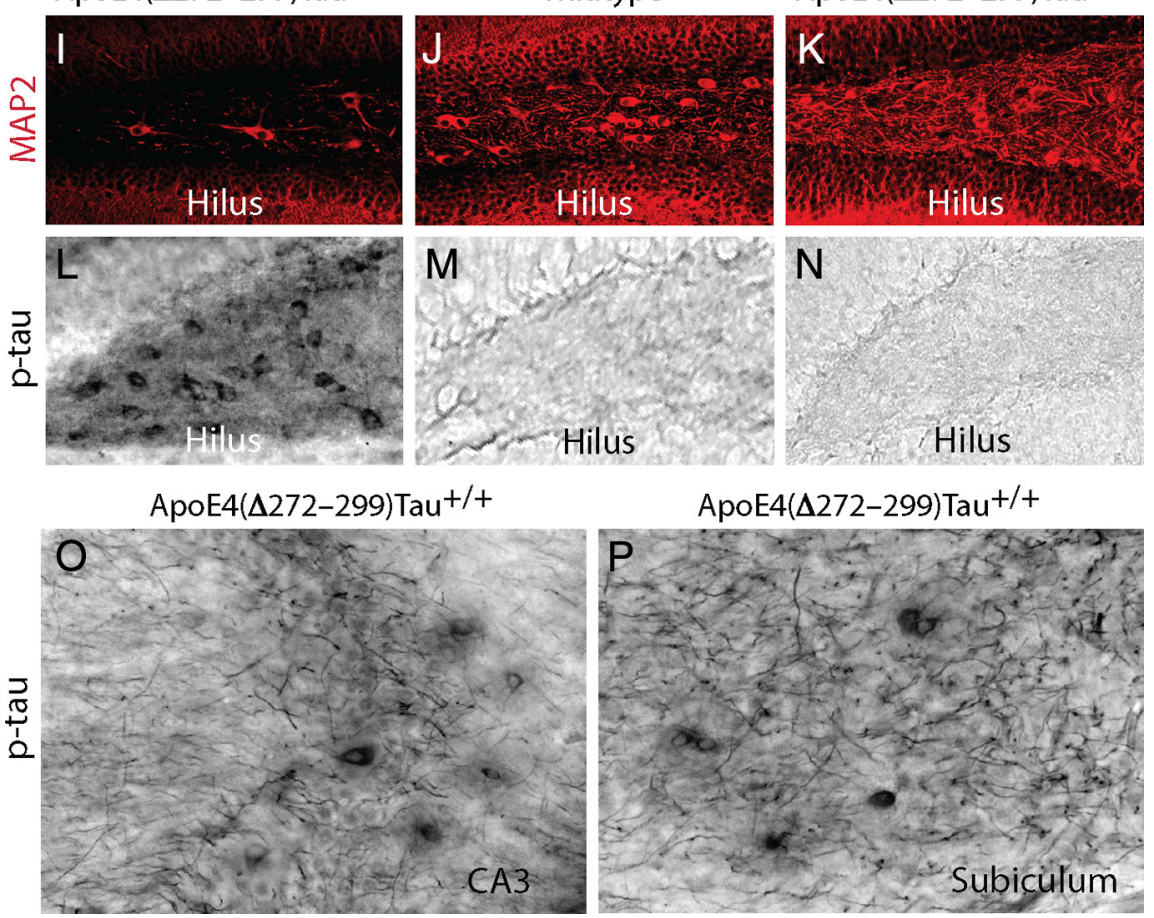

Figure 5. Localization of apoE4( $\Delta 272-299)$ in the hippocampus and its effects on neurodegeneration and Tau pathology in the presence and absence of Tau. $\boldsymbol{A}-\boldsymbol{D}$, Double immunofluorescence staining for apoE (green) and NeuN (red) in the hippocampus of apoE4( $\Delta 272-299) \mathrm{mE}^{-1-}$ Tau $^{+/+}$mice (magnification: $\left.\boldsymbol{A}, 100 \times ; \boldsymbol{B}-\boldsymbol{D}, 400 \times\right)$. E, Double immunofluorescence staining for apoE (green) and synaptophysin (Syn, red) in the CA3 region of apoE4 $(\Delta 272-299) \mathrm{mE}^{-1-} \mathrm{Tau}^{+/+}$mice $(600 \times)$. $\boldsymbol{F}$, Double immunofluorescence staining for apoE (green) and MAP2 (red) in the CA3 region of apoE4( $\Delta 272-299) \mathrm{mE}^{-1-} \mathrm{Tau}^{+/+}$mice (magnification, 600X). G, $\boldsymbol{H}$, Hematoxylin-eosin staining of the dentate gyrus of apoE4( $\Delta 272-299) \mathrm{mE}^{-/-} \mathrm{Tau}^{+/+}(\boldsymbol{G})$ and wild-type $(\boldsymbol{H})$ mice (magnification, $200 \times)$. $\boldsymbol{I}-\boldsymbol{K}$, Immunofluorescence staining for MAP2 in the hilus of the dentate gyrus of

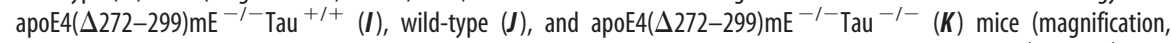
$200 \times)$. $L-N$, Anti-p-Tau (AT8 monoclonal antibody) immunostaining of the hilus of apoE4( $\Delta 272-299) \mathrm{mE}^{-1-} \mathrm{Tau}^{+/+}(\boldsymbol{L})$, $\mathrm{mE}^{-/-} \mathrm{Tau}^{+/+}(\boldsymbol{M})$, and apoE4$(\Delta 272-299) \mathrm{mE}^{-/-} \mathrm{Tau}^{-1-}(\boldsymbol{N})$ mice (magnification, $\left.400 \times\right)$ ) $\mathbf{0}, \boldsymbol{P}$, Anti-p-Tau (AT8 monoclonal antibody) immunostaining of the CA3 region (0) of the hippocampus and the subiculum $(\boldsymbol{P})$ of apoE4( $\Delta 272$ 299) $\mathrm{mE}^{-1-} \mathrm{Tau}^{+/+}$mice (magnification, $400 \times$ ). All mice were $11-13$ months of age. 


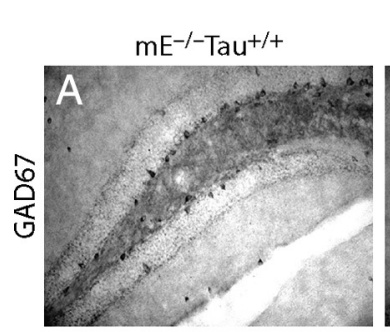

ApoE4( $\Delta 272-299)$

ApoE4( $\Delta 272-299)$ $\mathrm{mE}^{-/-} \mathrm{Tau}^{+/+}$
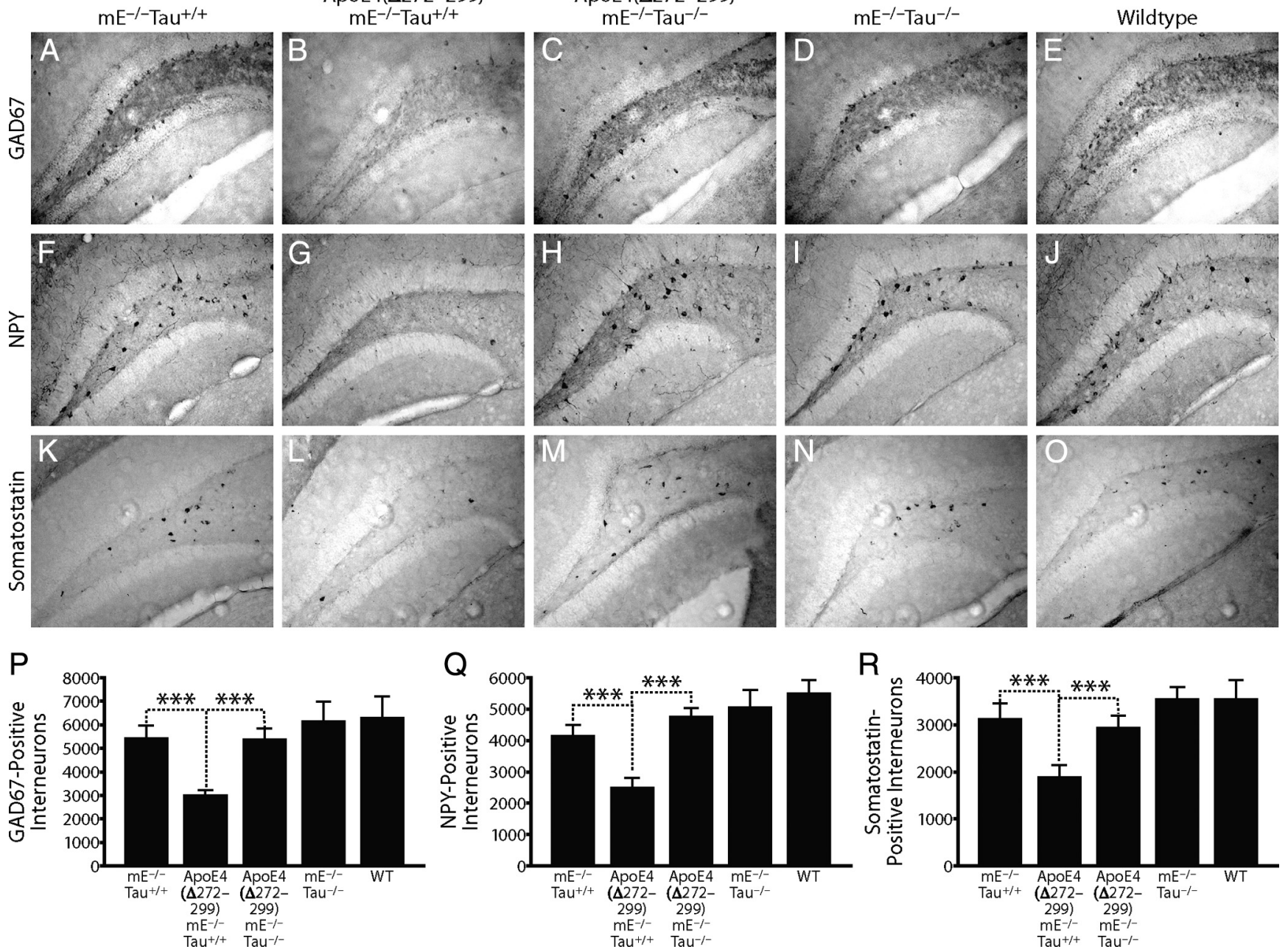

Figure 6. Loss of GABAergic interneurons in the hilus of the dentate gyrus of apoE4( $\Delta 272-299) \mathrm{mE}^{-/-}$Tau $^{+/+}$mice and rescue by Tau removal. The brains of $14 \mathrm{mE}^{-/-}$Tau $^{+/+}, 10$

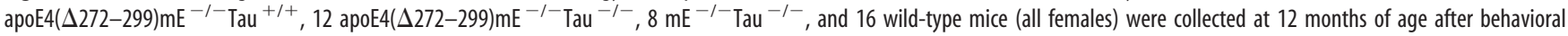
assessment, sectioned, and immunostained with antibodies against GAD67, neuropeptide Y (NPY), or somatostatin. $\boldsymbol{A}-\mathbf{0}$, Photomicrographs (200X) of GABAergic interneurons in the hilus after staining with anti-GAD67 $(\boldsymbol{A}-\boldsymbol{E})$, anti-NPY $(\boldsymbol{F}-\boldsymbol{J})$, or anti-somatostatin $(\boldsymbol{K}-\mathbf{0})$. $\boldsymbol{P}-\boldsymbol{R}$, Total number of GAD67-positive $(\boldsymbol{P})$, NPY-positive ( $\boldsymbol{Q})$, and somatostatin-positive $(\boldsymbol{R})$ GABAergic interneurons in the hilus. Values are mean \pm SEM. ${ }^{* * *} p<0.005$ ( $t$ test).

munostaining (Fig. 5G-J), and tau pathology as determined by anti-p-Tau (AT8 monoclonal antibody) immunostaining (Fig. $5 L, M, O, P)$ in the hilus of the dentate gyrus, the hippocampal CA3 area, and the subiculum. Strikingly, neurodegeneration and Tau pathology occurred earliest in the hilus (Fig. 5G-J,L).

Tau removal prevents loss of hilar GABAergic interneurons in female apoE4 $(\Delta 272-299)$ mice

Immunostaining for GAD67 (Fig. 6A-E), neuropeptide Y (NPY) (Fig. $6 \mathrm{~F}-\mathrm{J}$ ), and somatostatin (Fig. $6 \mathrm{~K}-\mathrm{O}$ ) revealed $40-50 \%$ fewer GABAergic interneurons in the hilus of apoE4 $(\Delta 272$ 299) $\mathrm{mE}^{-1-} \mathrm{Tau}^{+/+}$mice than in $\mathrm{mE}^{-1-} \mathrm{Tau}^{+/+}$mice (twotailed $t$ test; GAD67, $t_{(22)}=5.536, p<0.005$; NPY, $t_{(14)}=4.738$, $p<0.005$; somatostatin, $\left.t_{(14)}=3.964, p<0.005\right)$ or wild-type controls (two-tailed $t$ test; GAD67, $t_{(13)}=5.193, p<0.005$; NPY, $t_{(13)}=5.897, p<0.005$; somatostatin, $\left.t_{(13)}=4.031, p<0.005\right)$ (Fig. $6 P-R$ ). Eliminating Tau prevented neuronal deficits in apoE4 fragment transgenic mice, including loss of GABAergic interneurons in the hilus (two-tailed $t$ test; GAD67, $t_{(20)}=5.083, p<0.005 ; \mathrm{NPY}$, $t_{(20)}=8.685, p<0.005$; somatostatin, $t_{(20)}=3.991, p<0.005$ ) (Fig. 6 ), neurodegeneration (Fig. 5, compare $K$ to $I$ and $J$ ), and Tau pathology in hilar interneurons (Fig. 5, compare $N$ to $L$ and $M$ ).
In 14-day primary hippocampal neuronal cultures, immunostaining for GAD67 (Fig. 7A,B) revealed $\sim 50 \%$ fewer GABAergic neurons in cultures from apoE4 $(\Delta 272-299) \mathrm{mE}^{-/-} \mathrm{Tau}^{+/+}$mice than from $\mathrm{mE}^{-/-} \mathrm{Tau}^{+/+}$controls (two-tailed $t$ test; $t_{(24)}=2.595$, $p<0.01$ ) (Fig. 7E) and markedly lower GAD67 immunoreactivity in neurites of surviving GABAergic neurons (Fig. 7, compare $B$ to $A$ ). Tau removal increased the survival of GABAergic neurons from apoE4 $(\Delta 272-299) \mathrm{mE}^{-/-} \mathrm{Tau}^{-/-}$mice to levels higher than in $\mathrm{mE}^{-/-} \mathrm{Tau}^{+/+}$mice (two-tailed $t$ test; $t_{(23)}=3.49, p<0.01$ ) (Fig. $7 A-C, E)$. Removing Tau also increased the survival of GABAergic neurons from $\mathrm{mE}^{-1-} \mathrm{Tau}^{-1-}$ mice to levels higher than those of neurons from $\mathrm{mE}^{-/-} \mathrm{Tau}^{+/+}$mice (two-tailed $t$ test; $t_{(21)}=3.145$, $p<0.01$ ) (Fig. $7 A, D, E$ ). Thus, eliminating endogenous Tau rescues apoE4 fragment-caused GABAergic interneuron impairment both in mice and in primary hippocampal neuronal cultures.

Tau removal prevents spatial learning and memory deficits in female apoE4 $(\Delta 272-299)$ mice

To assess effects of Tau removal on learning and memory deficits induced by apoE4 fragments, we tested 12-month-old female mice in the Morris water maze. In the hidden platform trial, $\mathrm{mE}^{-/-} \mathrm{Tau}^{+/+}$and wild-type mice quickly learned the task, 


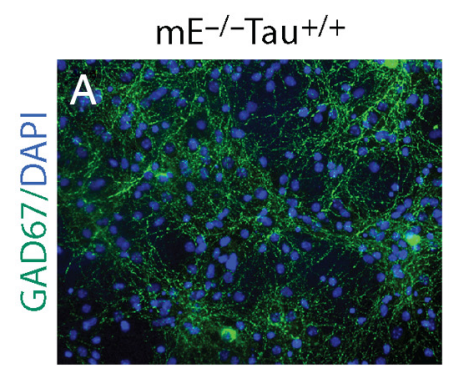

ApoE4( $272-299)$

ApoE4( $4272-299)$ $\mathrm{mE}^{-/-\mathrm{Tau}^{-/-}}$
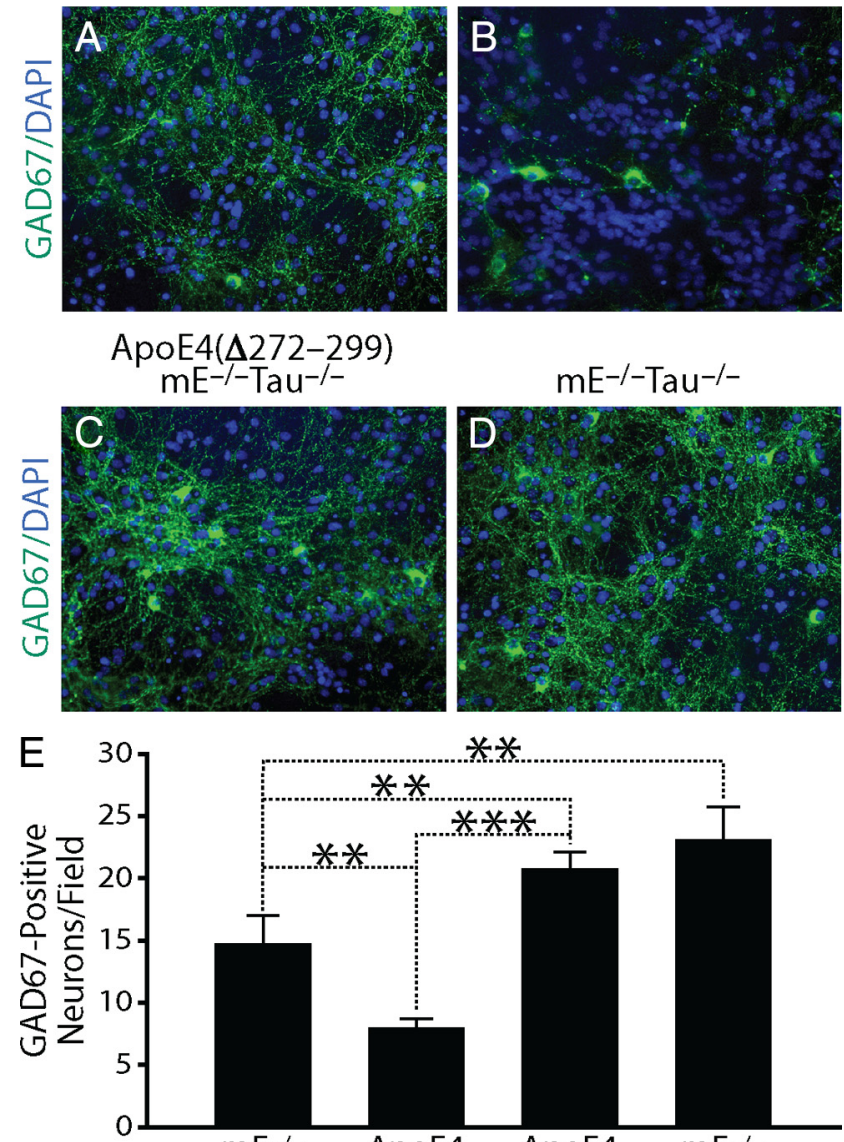

$* *$

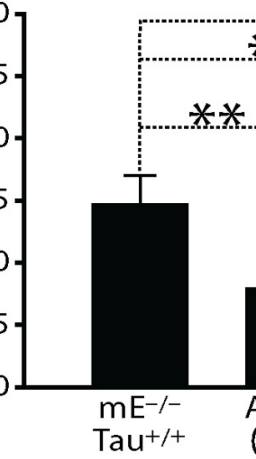

$+$

$* * \ldots+\cdots$
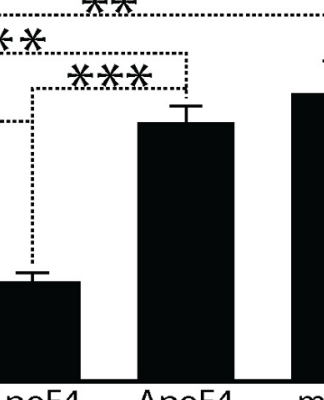

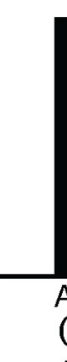$$
-299)
$$

$\mathrm{mE}^{-1-}$

$\mathrm{Tau}^{+/+}$

$-299)$

$\mathrm{mE}^{-1-}$

Figure 7. Eliminating Tau prevents the neurotoxic effect of apoE4 fragments on primary hippocampal GABAergic neurons. $\boldsymbol{A}-\boldsymbol{D}$, Primary hippocampal neurons from individual PO pups

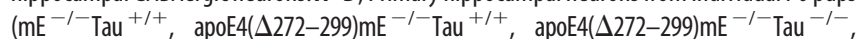
and $\mathrm{mE}^{-l-} \mathrm{Tau}^{-l-}$ ) were cultured for $14 \mathrm{~d}$ in vitro (DIV14) and double stained with antiGAD67 (green) and DAPI (blue). Shown are representative images collected from three mice of each genotype and five fields per coverslip (magnification, 200X). $\boldsymbol{E}$, Numbers of GAD67positive neurons were quantified as described in Materials and Methods. Values are mean \pm SEM. ${ }^{* *} p<0.01,{ }^{* * *} p<0.005$ ( $t$ test).

but apoE4 $(\Delta 272-299) \mathrm{mE}^{-/-} \mathrm{Tau}^{+/+}$mice showed a deficit [repeated-measures ANOVA; $F_{(4,55)}=10.24, p<0.001$; post hoc comparisons; apoE4 $4(\Delta 272-299) \mathrm{mE}^{-/-} \mathrm{Tau}^{+/+}$vs other groups, the smallest $t_{(20)}=3.537$, the biggest $p<0.01$ ] (Fig. 8A). Swim speeds of the mice did not differ (supplemental Fig. 4, available at www.jneurosci.org as supplemental material). ApoE4( $\Delta 272$ 299) $\mathrm{mE}^{-1-} \mathrm{Tau}^{-I-}$ mice performed as well as $\mathrm{mE}^{-1-} \mathrm{Tau}^{+/+}$ and wild-type mice in the hidden platform trial (Fig. $8 \mathrm{~A}$ ). Thus, Tau removal prevented the apoE4 fragment-induced learning deficit. In subsequent visible platform trials, all groups of mice performed equally well (Fig. $8 \mathrm{~A}$ ). In the probe trial $24 \mathrm{~h}$ after the

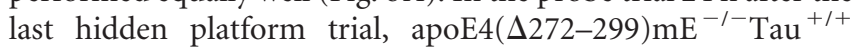
mice had deficits in the target crossing and target quadrant tests that were eliminated by Tau removal (Fig. $8 B, C$ ). Interestingly, in the elevated plus maze, which assesses hippocampus-independent anxiety, apoE4 $(\Delta 272-299) \mathrm{mE}^{-/-} \mathrm{Tau}^{+/+}$mice had abnormal anxiety that was unaffected by Tau removal (supplemental Fig. $5 \mathrm{~A}$, available at www.jneurosci.org as supplemental material), suggesting that elimination of Tau specifically affects hippocampus-dependent learning and memory performance.

Hilar GABAergic interneuron impairment correlates with spatial learning deficits in female apoE4 $(\Delta 272-299)$ mice with Tau In apoE4 $(\Delta 272-299) \mathrm{mE}^{-1-} \mathrm{Tau}^{+/+}$mice, the number of GABAergic interneurons in the hilus correlated inversely with escape latency on days $1-5$ of the hidden platform test (GAD67, $R^{2}=0.515, p<0.05, n=10$; somatostatin, $R^{2}=0.526, p<0.05$, $n=10$; NPY, $\left.R^{2}=0.410, p<0.05, n=10\right)$ (Fig. $8 D-F$ ). Importantly, as in apoE4-KI mice (Fig. $3 C, E, G)$, apoE4 $(\Delta 272$ 299) $\mathrm{mE}^{-1-} \mathrm{Tau}^{+/+}$mice with $<2500$ hilar GABAergic interneurons had greater learning deficits in the hidden platform trials (Fig. $8 D-F$ ), consistent with a threshold of $\sim 2500$ hilar GABAergic interneurons for normal versus impaired learning performance in the Morris water maze. The number of hilar GABAergic interneurons did not correlate with performance in visible platform trials in apoE4 $(\Delta 272-299) \mathrm{mE}^{-/-} \mathrm{Tau}^{+/+}$mice (supplemental Fig. $5 B-D$, available at www.jneurosci.org as supplemental material).

Tau removal prevents apoE4-induced learning and memory deficits by protecting against hilar GABAergic interneuron impairment Finally, we determined whether the rescue of learning and memory deficits by Tau removal reflects protection against GABAergic interneuron impairment. ApoE4 $(\Delta 272-299) \mathrm{mE}^{-/-} \mathrm{Tau}^{-\prime-}$ mice were treated with a subthreshold dose $(1 \mathrm{mg} / \mathrm{kg})$ of picrotoxin, a GABA receptor antagonist, to block GABA signaling. The rescue was abolished (Fig. 8G,H), but the number of hilar GABAergic interneurons was unaltered (supplemental Fig. $5 E$, available at www.jneurosci.org as supplemental material). Picrotoxin at this dose did not alter learning and memory in wild-type or $\mathrm{mE}^{-/-} \mathrm{Tau}^{+/+}$mice (supplemental Fig. $5 F, G$, available at www.jneurosci.org as supplemental material). In contrast, treatment of apoE4 $(\Delta 272-299) \mathrm{mE}^{-1-} \mathrm{Tau}^{+/+}$mice with pentobarbital, a $\mathrm{GABA}_{\mathrm{A}}$ receptor potentiator, rescued the learning deficit (supplemental Fig. $5 \mathrm{H}$, available at www.jneurosci. org as supplemental material). Evidently, Tau removal rescues apoE4 fragment-induced learning and memory deficits by preventing the loss of GABAergic interneurons.

\section{Discussion}

This study shows that female apoE4-KI mice have a significant age-dependent decrease in hilar GABAergic interneurons that correlates with the extent of apoE4-induced learning and memory deficits in aged mice. In neurotoxic apoE4 fragment transgenic mice, the interneuron loss was even more pronounced and correlated with the extent of learning and memory deficits. The interneuron loss and learning and memory deficits in these mice were prevented by Tau removal, and the prevention was abolished by blocking GABA signaling with picrotoxin. In both groups of mice, the $\mathrm{GABA}_{\mathrm{A}}$ receptor potentiator pentobarbital rescued the learning and memory deficits. Thus, apoE4 causes age- and Tau-dependent hilar GABAergic interneuron impairment, leading to learning and memory deficits in mice.

Roles of apoE4-caused GABAergic interneuron impairment in learning and memory deficits and Alzheimer's disease pathogenesis The GABAergic system appears to be important in the neuronal control of learning and memory. Learning triggers a rapid increase in inhibitory synaptogenesis and the GABA content of inhibitory synapses (Jasinska et al., 2010), accompanied by longlasting enhancement of synaptic inhibition onto excitatory neurons in mice (Brosh and Barkai, 2009). A novel environment and spatial learning also trigger a lasting increase in GABA release from 
A

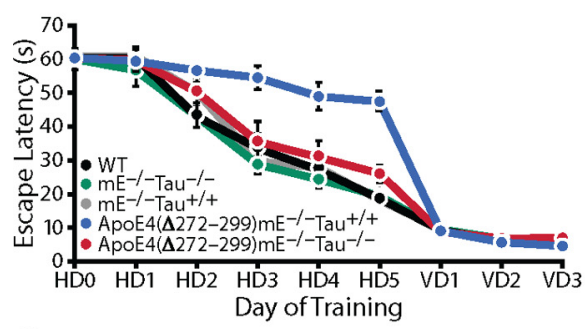

C

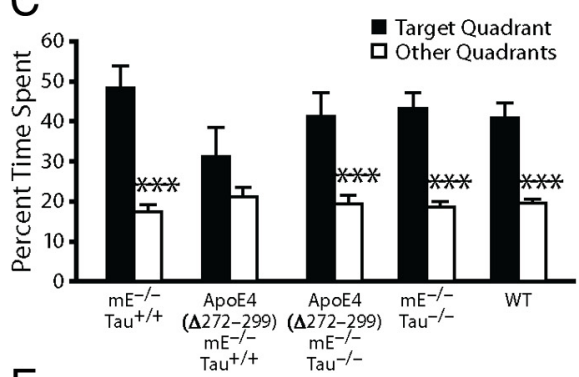

$E$

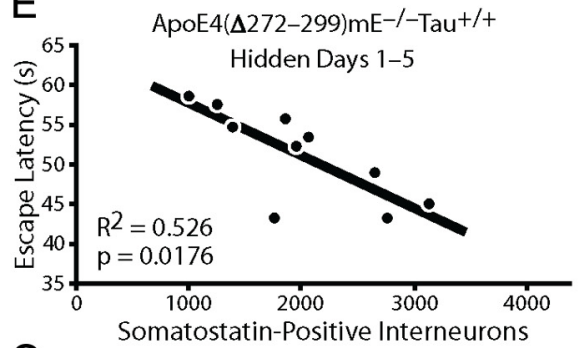

G

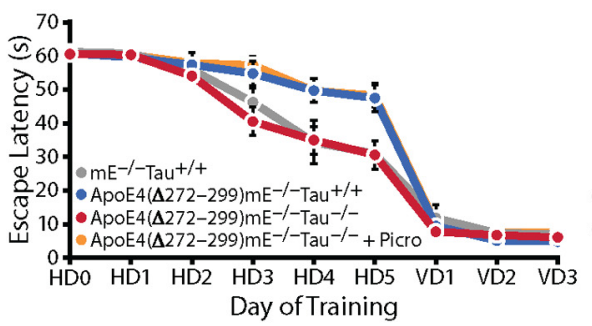

Day of Training
B

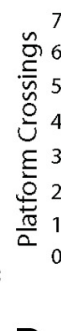

D

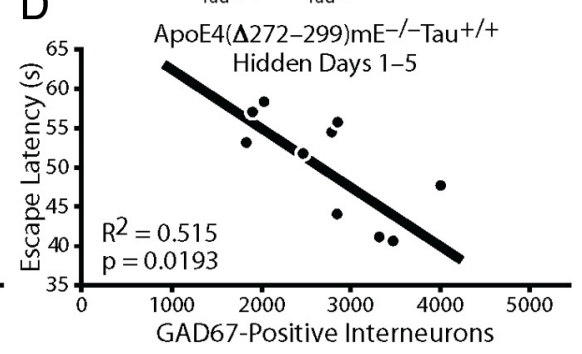

F

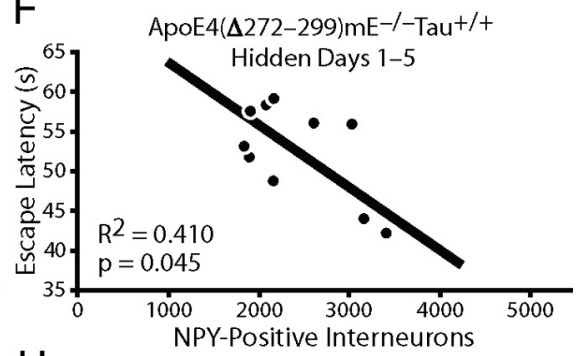

$\mathrm{H}$

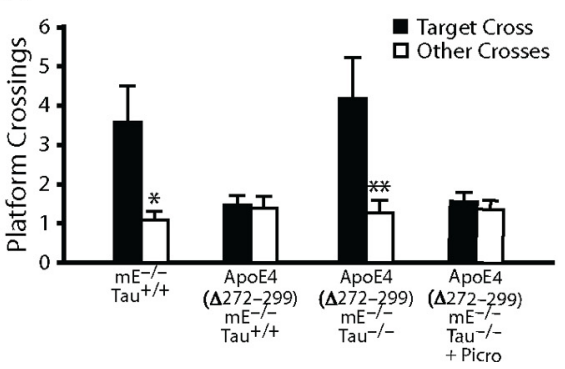

Figure 8. Spatial learning and memory deficits in apoE4( $\Delta 272-299) \mathrm{mE}^{-1-} \mathrm{Tau}^{+/+}$mice and rescue by Tau removal. $\boldsymbol{A}$,

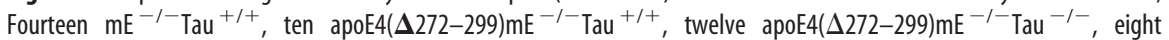
$\mathrm{mE}^{-1-} \mathrm{Tau}^{-1-}$, and sixteen wild-type mice (all females) were tested at 12 months of age in the Morris water maze. Values are mean \pm SEM. In the hidden platform days, learning curves differed significantly by genotype (repeated-measures ANOVA, $p<$ 0.001). In post hoc comparisons, apoE4( $\Delta 272-299) \mathrm{mE}^{-1-} \mathrm{Tau}^{+1+}$ mice learned poorly $(p<0.01$ vs other groups). ApoE4( $\Delta 272-299) \mathrm{mE}^{-1-} \mathrm{Tau}^{-I-}, \mathrm{mE}^{-/-} \mathrm{Tau}^{+/+}$, and wild-type mice performed at a similar level. $\boldsymbol{B}$, In the probe trial $24 \mathrm{~h}$ after the last hidden platform training, the number of target platform crossings versus crossings of the equivalent area in the other quadrants differed by genotype $(p<0.05)$. In post hoc comparisons, apoE4 $(\Delta 272-299) \mathrm{mE}^{-1-}$ Tau $^{-1-}$ mice performed better than apoE4 $(\Delta 272-299) \mathrm{mE}^{-/-} \mathrm{Tau}^{+/+}$mice $(p<0.01)$ in the target crossing test. Only apoE4 $(\Delta 272-299) \mathrm{mE}^{-/-} \mathrm{Tau}^{+/+}$ mice showed impaired memory in the probe trail, and the deficit was rescued by Tau removal. Values are mean \pm SEM. ${ }^{* * *} p<$ 0.005. C, In the probe trial $24 \mathrm{~h}$ after the last hidden platform training, the time spent in the target quadrant versus the other quadrants differed by genotypes $(p<0.01)$. In post hoc comparisons, only apoE4 $(\Delta 272-299) \mathrm{mE}^{-1-} \mathrm{Tau}^{+/+}$mice showed impaired memory in the probe test, and the deficit was rescued by Tau removal. Values are mean \pm SEM. ${ }^{* * *} p<0.005$. D-F, Latency on hidden days $1-5$ correlated inversely with the number of GAD67-positive $(\boldsymbol{D})$, somatostatin-positive $(\boldsymbol{E})$, and NPYpositive $(\boldsymbol{F})$ GABAergic interneurons in the hilus in apoE4 $(\Delta 272-299) \mathrm{mE}^{-1-}$ Tau $^{+/+}$mice. $n=10$ per analysis. $\boldsymbol{G}$, ApoE4( $\Delta 272-299) \mathrm{mE}^{-1-} \mathrm{Tau}^{-1-}$ mice were treated with picrotoxin (Picro, $1 \mathrm{mg} / \mathrm{kg}$ i.p.) or saline $(n=6-8$ per group) for $3 \mathrm{~d}$

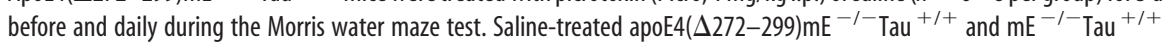
mice ( $n=6-8$ per group) served as controls. The learning curve of picrotoxin-treated apoE4( $\Delta 272-299) \mathrm{mE}^{-1-} \mathrm{Tau}^{-1-}$ mice resembled that of saline-treated apoE4( $\Delta 272-299) \mathrm{mE}^{-1-} \mathrm{Tau}^{+/+}$mice, which differed significantly from those of saline-treated controls $(p<0.01)$. Values are mean \pm SEM. $\boldsymbol{H}$, In the probe trial $24 \mathrm{~h}$ after the last hidden session, picrotoxin-treated apoE4 $(\Delta 272-299) \mathrm{mE}^{-/-} \mathrm{Tau}^{-/-}$mice performed significantly worse than saline-treated apoE4( $\Delta 272-$ $299) \mathrm{mE}^{-1-} \mathrm{Tau}^{-1-}(p<0.05)$ or $\mathrm{mE}^{-1-} \mathrm{Tau}^{+/+}$mice $(p<0.01)$ in the target crossing test. $n=6-8$ mice per group. Values are mean \pm SEM. ${ }^{*} p<0.05,{ }^{* *} p<0.01$. hippocampal GABAergic interneurons in mice (Nitz and McNaughton, 2004; Cui et al., 2008). Conversely, decreasing GABA levels in the hippocampus by overexpressing GABA transport 1 (GAT1), which is responsible for GABA reuptake after its synaptic release, impairs learning and memory in mice (Hu et al., 2004). Thus, learning appears to involve an increase in inhibitory synaptic plasticity and GABA release.

Dysfunction of the GABAergic system might contribute to cognitive impairment in humans. Alzheimer's disease patients have decreased GABA or somatostatin levels in the brain and CSF (Davies et al., 1980; Bareggi et al., 1982; Zimmer et al., 1984; Hardy et al., 1987; Seidl et al., 2001) that are exacerbated by apoE4 (Grouselle et al., 1998). A single nucleotide polymorphism (SNP) of the somatostatin gene is associated with increased risk for Alzheimer's disease in apoE4, but not apoE3, carriers (Vepsäläinen et al., 2007; Xue et al., 2009). Furthermore, GABA levels in human CSF decrease with age (Bareggi et al., 1982) — the strongest risk factor for Alzheimer's disease.

We found a significant age-dependent decrease in hilar GABAergic interneurons in apoE4-KI mice that correlated with apoE4-induced learning deficits in aged mice. Interestingly, a threshold number of hilar GABAergic interneurons $(\sim 2500)$ appeared to distinguish normal versus impaired learning performance in the Morris water maze. Importantly, in apoE4-KI mice, hilar GABAergic interneuron impairment preceded learning and memory deficits, and the deficits were rescued by treatment with the $\mathrm{GABA}_{\mathrm{A}}$ receptor potentiator pentobarbital. Thus, it is conceivable that apoE4 causes age-dependent impairment of hilar GABAergic interneurons, leading to learning and memory deficits in mice. Consequently, enhancing GABA signaling might be a strategy to treat Alzheimer's disease related to apoE4. Interestingly, apoE4 is associated with subclinical epileptiform activity under stress (Palop and Mucke, 2009) and increased brain activity at rest and in response to memory tasks in humans (Filippini et al., 2009; Dennis et al., 2010), probably reflecting impaired GABAergic inhibitory neuronal functions in humans. Thus, the importance of apoE4-caused GABAergic interneuron impairment in the pathogenesis of Alzheimer's disease warrants further studies in humans.

How does impairment of GABAergic interneurons by apoE4 lead to learning and memory deficits? Since learning and memory normally involve an increase in inhibitory synaptic plasticity and GABA release, apoE4-caused GABAergic interneuron im- 
pairment could contribute directly to learning and memory deficits. On the other hand, apoE4-caused GABAergic interneuron dysfunction can also lead to impairment of adult hippocampal neurogenesis in mice (Li et al., 2009). Adult hippocampal neurogenesis has been implicated in learning and memory processes (Zhao et al., 2008). Thus, the other possibility is that apoE4-caused GABAergic interneuron dysfunction leads to impaired adult hippocampal neurogenesis, which indirectly contributes to learning and memory deficits. Interestingly, boosting GABA signaling with pentobarbital also rescues apoE4-caused impairment of hippocampal neurogenesis in apoE4-KI mice (Li et al., 2009). Clearly, these two possibilities are not mutually exclusive and warrant further studies to dissect the mechanisms in detail.

It should be emphasized that we only tested female mice in the current study because they are more susceptible than male mice to apoE4-induced learning and memory deficits (Raber et al., 1998; Raber et al., 2000). Likewise, in humans, women with apoE4 have higher risk than men with apoE4 to develop Alzheimer's disease (Farrer et al., 1997). These raise the question of whether male apoE4-KI mice have a similar or less severe impairment of hilar GABAergic interneurons. Experimentally addressing this question in future studies could help to explain the gender difference in developing Alzheimer's disease in humans with apoE4.

\section{Importance of Tau in GABAergic interneuron impairment and learning and memory deficits caused by apoE4 and its fragment}

Tau removal rescued the learning and memory deficits in mice by preventing apoE4 fragment-caused GABAergic interneuron impairment in the hilus of the hippocampus. This highlights the importance of Tau (or p-Tau) in apoE4's contribution to Alzheimer's disease pathogenesis. ApoE is found in neurofibrillary tangles in Alzheimer's disease brains (Crowther, 1993; Huang, 2006b, 2010). ApoE3 and apoE4 appear to have different effects on Tau phosphorylation and aggregation (Strittmatter et al., 1994; Brecht et al., 2004; Huang, 2006a,b, 2010; Mahley et al., 2006). In transgenic mice, expression of human apoE4 in neurons, but not in astrocytes, increases Tau phosphorylation (Tesseur et al., 2000a,b; Brecht et al., 2004), consistent with a neuron-specific effect (Huang, 2006a,b, 2010; Mahley et al., 2006). Previously, we showed that apoE4 and its C-terminal-truncated fragments stimulate Tau phosphorylation and formation of intracellular neurofibrillary tangle-like inclusions in transgenic mice (Huang et al., 2001; Harris et al., 2003; Brecht et al., 2004). In primary hippocampal neuronal cultures, apoE4 impairs the survival of GABAergic interneurons by generating more neurotoxic apoE fragments and increasing the levels of p-Tau in GABAergic interneurons (Li et al., 2009). Here, Tau removal prevented GABAergic interneuron impairment and learning and memory deficits caused by apoE4 fragments in transgenic mice, providing direct in vivo evidence that apoE4 acts upstream of Tau in Alzheimer's disease pathogenesis, as suggested previously (Brecht et al., 2004; Harris et al., 2004b; Small and Duff, 2008).

$\mathrm{A} \beta$ peptides may act upstream of tau, stimulating tau phosphorylation and neurofibrillary tangle formation in human mutant Tau transgenic mice overproducing or injected with $\mathrm{A} \beta$ peptides (Götz et al., 2001; Lewis et al., 2001). Knock-out of Tau also abolishes $\mathrm{A} \beta$-induced neurotoxicity in primary neuronal cultures and behavioral deficits in transgenic mice, suggesting that Tau is essential for $\mathrm{A} \beta$-related detrimental effects both in vitro and in vivo (Rapoport et al., 2002; Roberson et al., 2007; Ittner et al., 2010). Thus, acting downstream of apoE4 and $\mathrm{A} \beta$ peptides, Tau or $\mathrm{p}$-Tau might be a general causative factor in
Alzheimer's disease pathogenesis. Therefore, reducing Tau may be an effective strategy to treat or prevent Alzheimer's disease.

In addition to Tau as a key mediator, other reported losses of function or gains of negative function of apoE4 might also contribute to the GABAergic interneuron impairment and learning and memory deficits. These include the dysregulation of neuronal signaling pathways, impairment of glucose metabolism and mitochondrial integrity and function, and decreased protein levels of apoE4 in the brain [for review, see Huang (2006a,b, 2010), Mahley et al. (2006), Hoe and Rebeck (2008), Bu (2009), Herz (2009), and Kim et al. (2009)]. Clearly, further studies are needed to determine the potential contributions of other apoE4-related losses of function or gains of negative function to GABAergic interneuron impairment and learning and memory deficits.

\section{References}

Bareggi SR, Franceschi M, Bonini L, Zecca L, Smirne S (1982) Decreased CSF concentrations of homovanillic acid and $\gamma$-aminobutyric acid in Alzheimer's disease. Age- or disease-related modifications? Arch Neurol 39:709-712.

Bell RD, Zlokovic BV (2009) Neurovascular mechanisms and blood-brain barrier disorder in Alzheimer's disease. Acta Neuropathol 118:103-113.

Bour A, Grootendorst J, Vogel E, Kelche C, Dodart J-C, Bales K, Moreau P-H, Sullivan PM, Mathis C (2008) Middle-aged human apoE4 targetedreplacement mice show retention deficits on a wide range of spatial memory tasks. Behav Brain Res 193:174-182.

Brecht WJ, Harris FM, Chang S, Tesseur I, Yu G-Q, Xu Q, Fish JD, WyssCoray T, Buttini M, Mucke L, Mahley RW, Huang Y (2004) Neuronspecific apolipoprotein E4 proteolysis is associated with increased tau phosphorylation in brains of transgenic mice. J Neurosci 24:2527-2534.

Brosh I, Barkai E (2009) Learning-induced enhancement of feedback inhibitory synaptic transmission. Learn Mem 16:413-416.

Brunden KR, Trojanowski JQ, Lee VMY (2009) Advances in tau-focused drug discovery for Alzheimer's disease and related tauopathies. Nat Rev Drug Discov 8:783-793.

Bu G (2009) Apolipoprotein E and its receptors in Alzheimer's disease: pathways, pathogenesis and therapy. Nat Rev Neurosci 10:333-344.

Caselli RJ, Dueck AC, Osborne D, Sabbagh MN, Connor DJ, Ahern GL, Baxter LC, Rapcsak SZ, Shi J, Woodruff BK, Locke DE, Snyder CH, Alexander GE, Rademakers R, Reiman EM (2009) Longitudinal modeling of age-related memory decline and the APOE $\varepsilon 4$ effect. N Engl J Med 361:255-263.

Corder EH, Saunders AM, Strittmatter WJ, Schmechel DE, Gaskell PC, Small GW, Roses AD, Haines JL, Pericak-Vance MA (1993) Gene dose of apolipoprotein E type 4 allele and the risk of Alzheimer's disease in late onset families. Science 261:921-923.

Crowther RA (1993) Tau protein and paired helical filaments of Alzheimer's disease. Curr Opin Struct Biol 3:202-206.

Cui Y, Costa RM, Murphy GG, Elgersma Y, Zhu Y, Gutmann DH, Parada LF, Mody I, Silva AJ (2008) Neurofibromin regulation of ERK signaling modulates GABA release and learning. Cell 135:549-560.

Davies P, Katzman R, Terry RD (1980) Reduced somatostatin-like immunoreactivity in cerebral cortex from cases of Alzheimer disease and Alzheimer senile dementia. Nature 288:279-280.

Dawson HN, Ferreira A, Eyster MV, Ghoshal N, Binder LI, Vitek MP (2001) Inhibition of neuronal maturation in primary hippocampal neurons from tau deficient mice. J Cell Sci 114:1179-1187.

Dennis NA, Browndyke JN, Stokes J, Need A, Burke JR, Welsh-Bohmer KA, Cabeza R (2010) Temporal lobe functional activity and connectivity in young adult APOE $\varepsilon 4$ carriers. Alzheimers Dement 6:303-311.

Farrer LA, Cupples LA, Haines JL, Hyman B, Kukull WA, Mayeux R, Myers RH, Pericak-Vance MA, Risch N, van Duijn CM (1997) Effects of age, sex, and ethnicity on the association between apolipoprotein E genotype and Alzheimer disease. A meta-analysis. JAMA 278:1349-1356.

Filippini N, MacIntosh BJ, Hough MG, Goodwin GM, Frisoni GB, Smith SM, Matthews PM, Beckmann CF, Mackay CE (2009) Distinct patterns of brain activity in young carriers of the APOE- $\varepsilon 4$ allele. Proc Natl Acad Sci U S A 106:7209-7214.

Götz J, Chen F, van Dorpe J, Nitsch RM (2001) Formation of neurofibrillary tangles in P301L tau transgenic mice induced by A $\beta 42$ fibrils. Science 293:1491-1495.

Grouselle D, Winsky-Sommerer R, David JP, Delacourte A, Dournaud P, 
Epelbaum J (1998) Loss of somatostatin-like immunoreactivity in the frontal cortex of Alzheimer patients carrying the apolipoprotein epsilon 4 allele. Neurosci Lett 255:21-24.

Hardy J, Selkoe DJ (2002) The amyloid hypothesis of Alzheimer's disease: progress and problems on the road to therapeutics. Science 297:353-356.

Hardy J, Cowburn R, Barton A, Reynolds G, Dodd P, Wester P, O'Carroll AM, Lofdahl E, Winblad B (1987) A disorder of cortical GABAergic innervation in Alzheimer's disease. Neurosci Lett 73:192-196.

Harris FM, Brecht WJ, Xu Q, Tesseur I, Kekonius L, Wyss-Coray T, Fish JD, Masliah E, Hopkins PC, Scearce-Levie K, Weisgraber KH, Mucke L, Mahley RW, Huang Y (2003) Carboxyl-terminal-truncated apolipoprotein E4 causes Alzheimer's disease-like neurodegeneration and behavioral deficits in transgenic mice. Proc Natl Acad Sci U S A 100:10966-10971.

Harris FM, Tesseur I, Brecht WJ, Xu Q, Mullendorff K, Chang S, Wyss-Coray T, Mahley RW, Huang Y (2004a) Astroglial regulation of apolipoprotein E expression in neuronal cells. Implications for Alzheimer's disease. J Biol Chem 279:3862-3868.

Harris FM, Brecht WJ, Xu Q, Mahley RW, Huang Y (2004b) Increased tau phosphorylation in apolipoprotein E4 transgenic mice is associated with activation of extracellular signal-regulated kinase: modulation by zinc. J Biol Chem 279:44795-44801.

Hartman RE, Wozniak DF, Nardi A, Olney JW, Sartorius L, Holtzman DM (2001) Behavioral phenotyping of GFAP-apoE3 and -apoE4 transgenic mice: ApoE4 mice show profound working memory impairments in the absence of Alzheimer's-like neuropathology. Exp Neurol 170:326-344.

Herz J (2009) Apolipoprotein E receptors in the nervous system. Curr Opin Lipidol 20:190-196.

Herz J, Beffert U (2000) Apolipoprotein E receptors: linking brain development and Alzheimer's disease. Nat Rev Neurosci 1:51-58.

Hoe HS, Rebeck GW (2008) Functional interactions of APP with the apoE receptor family. J Neurochem 106:2263-2271.

Hu JH, Ma YH, Jiang J, Yang N, Duan SH, Jiang ZH, Mei ZT, Fei J, Guo LH (2004) Cognitive impairment in mice over-expressing gammaaminobutyric acid transporter 1 (GAT1). Neuroreport 15:9-12.

Huang Y (2006a) Apolipoprotein E and Alzheimer disease. Neurology 66 [Suppl 1]:S79-S85.

Huang Y (2006b) Molecular and cellular mechanisms of apolipoprotein E4 neurotoxicity and potential therapeutic strategies. Curr Opin Drug Discov Dev 9:627-641.

Huang Y (2010) A $\beta$-independent roles of apolipoprotein E4 in the pathogenesis of Alzheimer's disease. Trends Mol Med 16:287-294.

Huang Y, Liu XQ, Wyss-Coray T, Brecht WJ, Sanan DA, Mahley RW (2001) Apolipoprotein E fragments present in Alzheimer's disease brains induce neurofibrillary tangle-like intracellular inclusions in neurons. Proc Natl Acad Sci U S A 98:8838-8843.

Irizarry MC, Rebeck GW, Cheung B, Bales K, Paul SM, Holzman D, Hyman BT (2000) Modulation of A $\beta$ deposition in APP transgenic mice by an apolipoprotein E null background. Ann N Y Acad Sci 920:171-178.

Ittner LM, Ke YD, Delerue F, Bi M, Gladbach A, van Eersel J, Wölfing H, Chieng BC, Christie MJ, Napier IA, Eckert A, Staufenbiel M, Hardeman E, Götz J (2010) Dendritic function of tau mediates amyloid- $\beta$ toxicity in Alzheimer's disease mouse models. Cell 142:387-397.

Jasinska M, Siucinska E, Cybulska-Klosowicz A, Pyza E, Furness DN, Kossut M, Glazewski S (2010) Rapid, learning-induced inhibitory synaptogenesis in murin barrel field. J Neurosci 30:1176-1184.

Kim J, Basak JM, Holtzman DM (2009) The role of apolipoprotein E in Alzheimer's disease. Neuron 63:287-303.

Lewis J, Dickson DW, Lin W-L, Chisholm L, Corral A, Jones G, Yen S-H, Sahara N, Skipper L, Yager D, Eckman C, Hardy J, Hutton M, McGowan E (2001) Enhanced neurofibrillary degeneration in transgenic mice expressing mutant tau and APP. Science 293:1487-1491.

Li G, Bien-Ly N, Andrews-Zwilling Y, Xu Q, Bernardo A, Ring K, Halabisky B, Deng C, Mahley RW, Huang Y (2009) GABAergic interneuron dysfunction impairs hippocampal neurogenesis in adult apolipoprotein E4 knockin mice. Cell Stem Cell 5:634-645.

Mahley RW (1988) Apolipoprotein E: cholesterol transport protein with expanding role in cell biology. Science 240:622-630.

Mahley RW, Weisgraber KH, Huang Y (2006) Apolipoprotein E4: A causative factor and therapeutic target in neuropathology, including Alzheimer's disease. Proc Natl Acad Sci U S A 103:5644-5651.

Namba Y, Tomonaga M, Kawasaki H, Otomo E, Ikeda K (1991) Apolipoprotein $\mathrm{E}$ immunoreactivity in cerebral amyloid deposits and neurofi- brillary tangles in Alzheimer's disease and kuru plaque amyloid in Creutzfeldt-Jakob disease. Brain Res 541:163-166.

Nitz D, McNaughton B (2004) Differential modulation of CA1 and dentate gyrus interneurons during exploration of novel environments. J Neurophysiol 91:863-872.

Palop JJ, Mucke L (2009) Epilepsy and cognitive impairments in Alzheimer disease. Arch Neurol 66:435-440.

Perrin RJ, Fagan AM, Holtzman DM (2009) Multimodal techniques for diagnosis and prognosis of Alzheimer's disease. Nature 461:916-922.

Raber J, Wong D, Buttini M, Orth M, Bellosta S, Pitas RE, Mahley RW, Mucke $\mathrm{L}$ (1998) Isoform-specific effects of human apolipoprotein $\mathrm{E}$ on brain function revealed in $A p o E$ knockout mice: increased susceptibility of females. Proc Natl Acad Sci U S A 95:10914-10919.

Raber J, Wong D, Yu G-Q, Buttini M, Mahley RW, Pitas RE, Mucke L (2000) Apolipoprotein E and cognitive performance. Nature 404:352-354.

Rapoport M, Dawson HN, Binder LI, Vitek MP, Ferreira A (2002) Tau is essential to $\beta$-amyloid-induced neurotoxicity. Proc Natl Acad Sci U S A 99:6364-6369.

Roberson ED, Scearce-Levie K, Palop JJ, Yan F, Cheng IH, Wu T, Gerstein H, Yu G-Q, Mucke L (2007) Reducing endogenous tau ameliorates amyloid $\beta$-induced deficits in an Alzheimer's disease mouse model. Science 316:750-754.

Seidl R, Cairns N, Singewald N, Kaehler ST, Lubec G (2001) Differences between GABA levels in Alzheimer's disease and Down syndrome with Alzheimer-like neuropathology. Naunyn Schmiedebergs Arch Pharmacol 363:139-145.

Selkoe DJ (1991) The molecular pathology of Alzheimer's disease. Neuron 6:487-498.

Small SA, Duff K (2008) Linking A $\beta$ and tau in late-onset Alzheimer's disease: a dual pathway hypothesis. Neuron 60:534-542.

Strittmatter WJ, Saunders AM, Schmechel D, Pericak-Vance M, Enghild J, Salvesen GS, Roses AD (1993) Apolipoprotein E: high-avidity binding to $\beta$-amyloid and increased frequency of type 4 allele in late-onset familial Alzheimer disease. Proc Natl Acad Sci U S A 90:1977-1981.

Strittmatter WJ, Saunders AM, Goedert M, Weisgraber KH, Dong L-M, Jakes R, Huang DY, Pericak-Vance M, Schmechel D, Roses AD (1994) Isoform-specific interactions of apolipoprotein $\mathrm{E}$ with microtubuleassociated protein tau: implications for Alzheimer disease. Proc Natl Acad Sci U S A 91:11183-11186.

Sullivan PM, Mace BE, Maeda N, Schmechel DE (2004) Marked regional differences of brain human apolipoprotein E expression in targeted replacement mice. Neuroscience 124:725-733.

Tanzi RE, Bertram L (2001) New frontiers in Alzheimer's disease genetics. Neuron 32:181-184.

Tesseur I, Van Dorpe J, Bruynseels K, Bronfman F, Sciot R, Van Lommel A, Van Leuven F (2000a) Prominent axonopathy and disruption of axonal transport in transgenic mice expressing human apolipoprotein E4 in neurons of brain and spinal cord. Am J Pathol 157:1495-1510.

Tesseur I, Van Dorpe J, Spittaels K, Van den Haute C, Moechars D, Van Leuven F (2000b) Expression of human apolipoprotein E4 in neurons causes hyperphosphorylation of protein tau in the brains of transgenic mice. Am J Pathol 156:951-964.

Vepsäläinen S, Helisalmi S, Koivisto AM, Tapaninen T, Hiltunen M, Soininen H (2007) Somatostatin genetic variants modify the risk for Alzheimer's disease among Finnish patients. J Neurol 254:1504-1508.

Weisgraber KH (1994) Apolipoprotein E: structure-function relationships. Adv Protein Chem 45:249-302.

Wisniewski T, Frangione B (1992) Apolipoprotein E: a pathological chaperone protein in patients with cerebral and systemic amyloid. Neurosci Lett 135:235-238.

Xu Q, Walker D, Bernardo A, Brodbeck J, Balestra ME, Huang Y (2008) Intron-3 retention/splicing controls neuronal expression of apolipoprotein E in the CNS. J Neurosci 28:1452-1459.

Xue S, Jia L, Jia J (2009) Association between somatostatin gene polymorphisms and sporadic Alzheimer's disease in Chinese population. Neurosci Lett 465:181-183.

Zhao C, Deng W, Gage FH (2008) Mechanisms and functional implications of adult neurogenesis. Cell 132:645-660.

Zhong N, Weisgraber KH (2009) Understanding the association of apolipoprotein E4 with Alzheimer's disease: clues from its structure. J Biol Chem 284:6027-6031.

Zimmer R, Teelken AW, Trieling WB, Weber W, Weihmayr T, Lauter H (1984) $\gamma$-Aminobutyric acid and homovanillic acid concentration in the CSF of patients with senile dementia of Alzheimer's type. Arch Neurol 41:602-604. 